\title{
A novel Dynamic Pareto bi-level Multi-Objective Particle Swarm Optimization (DPb-MOPSO) algorithm
}

\author{
Ahlem Aboud, Member, IEEE, Raja Fdhila, Amir Hussain and Adel M. Alimi Senior Member, IEEE
}

\begin{abstract}
Distributed architecture-based Particle Swarm Optimization is very useful for static optimization and not yet explored to solve complex dynamic multi-objective optimization problems. This study proposes a novel Dynamic Pareto bi-level Multi-Objective Particle Swarm Optimization (DPb-MOPSO) algorithm with two optimization levels. In the first level, all solutions are optimized in the same search space and the second level is based on a distributed architecture using the Pareto ranking operator for dynamic multi-swarm subdivision. The proposed approach adopts a dynamic handling strategy using a set of detectors to keep track of change in the objective function that is impacted by the problem's time-varying parameters at each level. To ensure timely adaptation during the optimization process, a dynamic response strategy is considered for the reevaluation of all non-improved solutions, while the worst particles are replaced with a newly generated one. The convergence and diversity performance of the DPb-MOPSO algorithm are proven through Friedman Analysis of Variance, and the Lyapunov theorem is used to prove stability analysis over the Inverted Generational Distance (IGD) and Hypervolume Difference (HVD) metrics. Compared to other evolutionary algorithms, the novel $\mathrm{DPb}-\mathrm{MOPSO}$ is shown to be most robust for solving complex problems over a range of changes in both the Pareto Optimal Set and Pareto Optimal Front.
\end{abstract}

Index Terms-Dynamic Multi-Objective Optimization, Dynamic Particle Swarm Optimization, Dynamic Problems, Detectors, Dynamic Response, Friedman Analysis of Variance, Lyapunov Theorem.

\section{INTRODUCTION}

$\mathbf{R}$ ECENTLY, the main issue facing optimization has focused on the challenging field of Dynamic MultiObjective Problems (DMOPs) with two or three conflicting functions characterized by dynamic objectives, parameters and/or constraints. A great deal of research conducts on Multi-Objective Evolutionary Algorithms (MOEAs) for solving static single and multi-objective problems referred to as SOPs and MOPs respectively are adapted for DMOPs [9], [32], [33] using a powerful range of bio-inspired intelligent techniques like the Genetic Algorithm (GA) [15] and the Particle Swarm Optimization (PSO) [6], [28]-[30]. These

A. Aboud is with University of Sousse, ISITCom, 4011, Sousse, Tunisia; and University of Sfax, National Engineering School of Sfax (ENIS), REGIMLab.: REsearch Groups in Intelligent Machines, LR11ES48, 3038, Sfax, Tunisia (e-mail: aboud.ahlem.tn@ieee.org).

R. Fdhila and A. M. Alimi are with the University of Sfax, National Engineering School of Sfax (ENIS), REGIM-Lab.: REsearch Groups in Intelligent Machines, LR11ES48, 3038, Sfax, Tunisia. (e-mails: raja.fdhila@ieee.org, adel.alimi@ieee.org).

A. Hussain is with Edinburgh Napier University, School of Computing, Edinburgh EH10 5DT, Scotland, U.K. (e-mail: a.hussain@napier.ac.uk). algorithms are designed to resolve evolutionary stagnation issues. In dynamic optimization, any MOEA should be able not only to find the best set of compromised solutions over Pareto Optimal Set (POS) and Pareto Optimal Front (POF) but also to track the changes that can affect. Several variants of PSO algorithm are modified for solving dynamic SOP (DSOP) when the standard PSO cannot be used for DMOP without modification because of the dual issues of outdated memory and the loss of diversity that needs crucial actions to be undertaken like change detection, memory update and diversity enhancement. Four types of DMOPs have classified by Farina et al. [22], in type I the POS change and the POF remains the same, but for type II both POS and POF change over time. However the POF change and the POS remains constant for DMOPs in type III. Despite the environmental changes both POS and POF still unchanged in type IV.

Several detection techniques are developed to tackle timedependent issues. The re-evaluation of objectives and constraints' values of certain percentage or randomly selected outdated population are very useful. Different response strategies using explicit actions like the re-initialization or hypermutation of populations is considered for ensuring fast convergence and diversity [1], [26]. PSO-based approaches are very considered for solving DSOP and a few methods are designed to solve DMOPs [2]. Nonetheless, distributed methods using genetic and population-based strategies have been shown to be important for static optimization [7] which has not been treated for handling the DMOPs.

To the best of our knowledge, does not exist any developed approach using the multi-objective particle swarm optimization (MOPSO) with distributed architecture for solving DMOPs. For that reason, the main motivation underlying this study presents the proposed Dynamic Pareto bi-level MultiObjective Particle Swarm Optimization (DPb-MOPSO) based on a distributed architecture for handling DMOPs with various types of changes on POS and POF. The distributed architecture of DPb-MOPSO is presented over upper and lower level for distribution and diversity amelioration. For the upper level, all individuals are optimized in the same research space. Nevertheless, the second lower level provides a distributed architecture using a dynamic multi-swarm subdivision based on the Pareto Ranking operator. Filling the contradictory gaps of convergence and diversity that leads to the algorithm losing its ability to react efficiently to changes. The DPb-MOPSO presents a dynamic handling strategy to effectively detect and react to the change. The detection strategy has carried out 
using a ten percent of solutions as detectors. The response strategy aims to re-evaluate all solutions with negative change to be replaced with new generated ones and the solutions with positive progress are adapted to accelerate optimization after each change.

So far, the state of the art involves a wealth of comparable algorithms to our novel DPb-MOPSO system over two performance metrics [26] namely the Inverted Generational Distance (IGD) and the Hypervolume Difference (HVD). These include the Multi-objective Evolutionary Algorithm Based on Decomposition (MOEAD) [31], the Dual multi-objective particle swarm optimization (dMOPSO) [18], the Dynamic Non-dominated Sorting Genetic Algorithm II (DNSGA-II) [14], the distributed Multi-Objective Particles Swarms Optimization, based on dynamic subdivision of the population using Pareto fronts (pbMOPSO) [7], the Dynamic Multiobjective Particle Swarm Optimization (Dynamic-MOPSO) [2], the dynamic Competitive-cooperative co-evolutionary Algorithm (dCOEA) [8], the Population Prediction Strategy (PPS) [34], the Steady-State and Generational Evolutionary Algorithm (SGEA) [13] and the Multi-Objective Particles Swarms Optimization (MOPSO) [5].

The rest of this paper has organized as follows. Section II presents an overview of dynamic multi-objective optimization methods. Section III details the proposed DPb-MOPSO. Section IV introduced preliminaries of the experimental study. Section V, describes the experimental results through Friedman Analysis of Variance overall quantitative results, furthermore a stability analysis has presented using Lyapunov theorem in Section VI. Finally, Section VII concluded this paper and suggested some perspectives for future works.

\section{Overview of Dynamic Multi-Objective OPTIMIZATION METHODS}

In dynamic optimization, we aim to optimize a dynamic problem $f_{t}$ with $m$ objective functions by an algorithm $G$ at a given period $\left[t_{\text {begin }}, t_{\text {end }}\right]$ such as presented in the following mathematical definition.

$$
\begin{aligned}
& \text { Min } F(x, t)=\left(f_{1}(x, t), f_{2}(x, t), \ldots, f_{n_{m}}(x, t)\right) \\
& \text { Subjectto }: g_{i}(x, t) \leq 0, i=1, \ldots, n_{g} \\
& h_{j}(x, t)=0, j=1, \ldots, n_{h} \\
& x \in\left[\mathrm{x}_{\text {min }}, x_{\text {max }}\right]^{n_{x}}, t \in\left[\mathrm{t}_{\text {begin }}, t_{\text {end }}\right]
\end{aligned}
$$

Several existing studies [26] have focused on three research levels, including the development of an exhaustive set of challenging dynamic benchmarks, the development of new algorithms for handling various dynamic problems and the development of efficient quality indicators to measure the performance of MOEAs. Many investigations have been carried out to encourage researchers to develop DMOPs instead of DSOPs. For example, the continuous FDA functions [22] with dynamic shift of POF and POS, the five ZJZ (F5 to F10) [34] with a non-linear correlation between the decision variables and the nine Unconstrained Dynamic Functions (UDFs) [27]. The challenge of dynamic optimization does not limit to the development of generic benchmarks, but it has interested also for solving dynamic real-world problems [23]. In literature, a powerful set of MOEAs is designed to address the static
MOPs [11], [15], [16] are used for solving DMOPs. During the last decade, several challenging approaches are developed for solving a powerful ranges of DMOPs. Those approaches are classified into four categories as resumed in Table I and detailed as follow; Firstly, the diversity-based methods are used to preserve population diversity through the reinitialization or hyper-mutation behavior after each transition or throughout the execution time like the variations Dynamic NSGA-II (DNSGA-II-A and DNSGA-II-B) [14] that aims to identify a random solution to be re-evaluated to monitor environmental change or to replace a percentage of the new population with new randomly generated solutions. Also, the DC-NSGA-II [24] algorithm presents a self-adaptive penalty function to deal with time-varying constraint problems. Thus, the Dynamic-MOPSO system [2] adapts a dynamic handling strategy to detect changes by controlling the evolution of the objective function over time and re-initialize all solutions with negative changes to maintain diversity.

In addition, several memory-based techniques [8], [13], [25], [27] are considered over an extra memory mechanism to implicitly or explicitly store the useful information and outdated solutions for potential uses. Furthermore, change prediction-based approaches were achieved to exploit past information and anticipate the new position of POS using a prediction model to reduce the number of function evaluations [3]. In [10] the D-QMOO algorithm was proposed based on the Feed-forward Prediction Strategy (FPS) to study the size and the distribution of the anticipatory solutions over time. Also, the Population Prediction Strategy (PPS) [17] is developed to predict a totality of solutions instead of using some isolated point. Finally, the parallel methods are implemented using multiple sub-populations mechanisms like the master-slave method in [20], [21], the independent runs, the island model and the cellular EAs. The DMOEA [33] adapts the subpopulation technique to solve a single objective problem. In this case study, a dynamic version of the MOPSO method is considered over a distributed architecture. The standard MOPSO algorithm safer from the stagnation at local optima and loss the diversity over time. Generally, the re-initialization strategy is the most useful technique to address the issues of population diversity after environmental changes. In addition, there is no approach using MOPSO with distributed architecture for solving DMOPs.

For the performance assessment metrics [26] four categories are classified as follows: the first deals with the accuracy measurement like Generational Distance (GD), variable space generational distance (VD) and Success Ratio (SR). The second aims to measure diversity such as Maximum Spread (MS), Coverage Scope (CS) and Path Length measure (PL). The third presents the robustness indicators like stability measure (stb) and reactivity measure (react). Ultimately, the last one shown a combined performance for convergence and diversity measurement like the accuracy, Inverted Generational Distance (IGD), Hypervolum (HV), Hypervolume difference (HVD) and $\mathrm{HV}$ ratio. 
TABLE I: Dynamic Multi-Objective Optimization Methods

\begin{tabular}{|c|c|}
\hline Algorithms & Tested Benchmark Function \\
\hline \multicolumn{2}{|c|}{ MOO algorithms adapted for DMOOP } \\
\hline SPEA2 , Kim M.(2004) [16] & \multirow{3}{*}{ DSW1, DSW2, DTF, FDA DMOPs } \\
\hline Multiple Single Objective Pareto Sampling (MSOPS), E. J. Hughes (2003) [11] & \\
\hline NSGA-II, Deb et al., (2002) [15] & \\
\hline \multicolumn{2}{|c|}{\begin{tabular}{|l} 
Diversity-Based Approaches \\
\end{tabular}} \\
\hline Modified NSGA-II : (DNSGA-II)-A and (DNSGA-II)-B, Deb et al., (2007) [14] & Modified FDA2 and hydro-thermal scheduling problem \\
\hline Dynamic Constrained NSGA-II (DC-NSGA-II), Azzouzet al., (2015) [24] & DCTPs test problems \\
\hline Dynamic-MOPSO Aboud et al., (2017) [2] & FDA1, DIMP2 and dMOP3 \\
\hline \multicolumn{2}{|c|}{\begin{tabular}{|lll} 
& Memory-Based Approaches \\
\end{tabular}} \\
\hline Steady-state and Generational EA (SGEA) Jiang et al., (2016) [13] & five FDA [22], three dMOP [8], six ZJZ [34] and seven UDF [27] \\
\hline Adaptive Dynamic NSGA-II (A-Dy-NSGA-II), Azzouz et al., (2017) [25] & FDA1, FDA2, DMZDT test functions and WYL \\
\hline Dynamic Competitive Cooperative CO-EA (dCOEA), Gohet al., (2009) [8] & FDA1, dMOP1, dMOP2 and dMOP3 \\
\hline \multicolumn{2}{|c|}{\begin{tabular}{|l} 
Change Prediction-Based Approaches \\
\end{tabular}} \\
\hline Population Prediction Strategy (PPS), Koo et al., (2010) [17] & FDA1, FDA4, dMOP1, dMOP2 and F5-F8 \\
\hline Dynamic MOEA with Predicted Re-Initialization (DMOEA/PRI), Zhou et al., (2007) [3] & FDA1 and ZJZ \\
\hline Dynamic Queuing MO Optimizer (D-QMOO), Hatzakis and Wallace (2006) [10] & FDA1 \\
\hline \multicolumn{2}{|l|}{\begin{tabular}{|cc} 
& Parallel Approaches
\end{tabular}} \\
\hline Work of Cámara et al., (2008) [21] & FDA1, modified FDA2 and FDA3 \\
\hline Dynamic Multi-objective Optimization EA (DMOEA), Zheng (2007) [33] & FDA1, modified FDA2 and FDA3, FDA4 and FDA5 \\
\hline Dynamic Version of Parallel Single Front Genetic Algorithm (PSFGA), Cámara et al., (20 & FDA1 and FDA2 \\
\hline
\end{tabular}

\section{The Proposed Dynamic Pareto Bi-LeVel Multi-ObJective Particle SWARM Optimization}

The proposed Dynamic Pareto bi-level Multi-Objective Particle Swarm Optimization (DPb-MOPSO) approach is shown in Figure 1presenting two optimization levels called the upper $\left(L_{1}\right)$ and the lower $\left(L_{2}\right)$ levels described in the following sub-sections A and B and detailed in Algorithms 1 and 2 respectively. The two levels have included a dynamism handling strategy to detect and react effectively to the changes. The utility of bi-level optimization is proved over a distributed architecture to give more opportunity for the system to enhance convergence with better distribution over time. The proposed system is executed until a maximum number of iterations $T_{\max }$ subdivided as follows: $50 \%$ for $L_{1}, 25 \%$ for $L_{2}$ and $25 \%$ for the re-execution step on $L_{1}$.

\section{A. DPb-MOPSO: Upper Level $\left(L_{1}\right)$}

The upper level $\left(L_{1}\right)$ is detailed in Algorithm 1 and started with random initialization of all particles $p_{i}$ in the swarm $\mathrm{S}$ and the leaders archive $A_{1}$. Each particle is a candidate solution $x_{i}^{*}$ in $n$ dimensional search space. For each particle $p_{i}$, we select a leader $A_{i}$ based on the crowding distance operator between two random particles. The particle with the lowest value is selected as leader, then we calculate the fitness function $F_{i}$ of each particle and update its position $(X)$ and velocity $(V)$ based on their self-experience $\left(p_{\text {best }}\right)$ as a local component and the experience of their neighbors $\left(g_{\text {best }}\right)$ as a global component using 2 and 3 respectively. This level is executed until 50\% of $T_{\max }$.

$$
\begin{gathered}
X_{t+1}=X_{t}+V_{t+1} \\
V_{t+1}=w V_{t}+c_{1} r_{1}\left(p_{\text {best }}(t)-X_{t}\right)+c_{2} r_{2}\left(g_{\text {best }}(t)-X_{t}\right)
\end{gathered}
$$

Where; $w$ is the inertia weights, $c_{1}$ and $c_{2}$ are acceleration coefficients. $r_{1}$ and $r_{2}$ are two parameters aiming to influence of the cognitive and social components of each particle. In Addition, all the changes are known for the algorithm and checked according to the frequency $\tau_{t}$ assuming timedependent parameters $t$ for each problem, where $t=\frac{1}{n_{t}}\left\lfloor\frac{\tau}{\tau_{t}}\right\rfloor$, $\forall t \in T$, with; $n_{t}, \tau$ and $\tau_{t}$ are the severity, the iteration

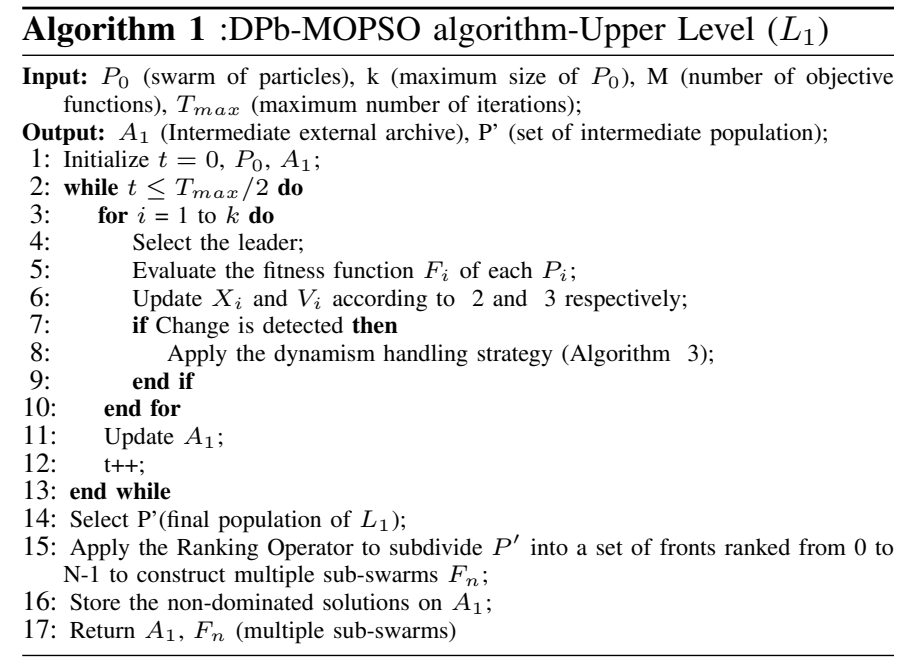

counter and the frequency of change respectively. If a change is detected on all the objective values, the dynamism handling strategy detailed in the subsection $\mathrm{C}$ and the algorithm 3 is executed. Furthermore, all the optimal solutions $X_{i}^{*}$ are saved into the archive $A_{1}$ using the $\epsilon$ operator to measure the best approximation for the true POF at the end of $\left(L_{1}\right)$.

\section{B. DPb-MOPSO: Lower Level $\left(L_{2}\right)$}

At half the maximum number of iterations $T_{\max } / 2$ of $\left(L_{1}\right)$, the switched level $\left(L_{2}\right)$ over a distributed architecture is started with the extraction of the intermediate population $P^{\prime}(P O S)$. Then, the Pareto Ranking Operator is applied to subdivide $P^{\prime}(P O S)$ into $N$ sub-swarms presenting the set of fronts denoted by $F_{0}, F_{1}, \ldots, F_{n}$. In most of the cases, the front $F_{0}$ has the maximum number of solutions. So, for ensuring equality between fronts size, all extra-individuals from $F_{0}$ are injected into other fronts. For each front $F_{i}$; where i $=$ $0 \ldots \mathrm{N}-1$, the DPb-MOPSO algorithm in $\left(L_{1}\right)$ is re-executed in a parallel execution until $25 \%$ of $T_{\max }$ and all the nondominated solutions are stored in $A_{2}$. In addition, all the non-dominated solutions of $\left(L_{2}\right)$ are regrouped to construct a second intermediate population $P$ "and re-executed in $\left(L_{1}\right)$ 


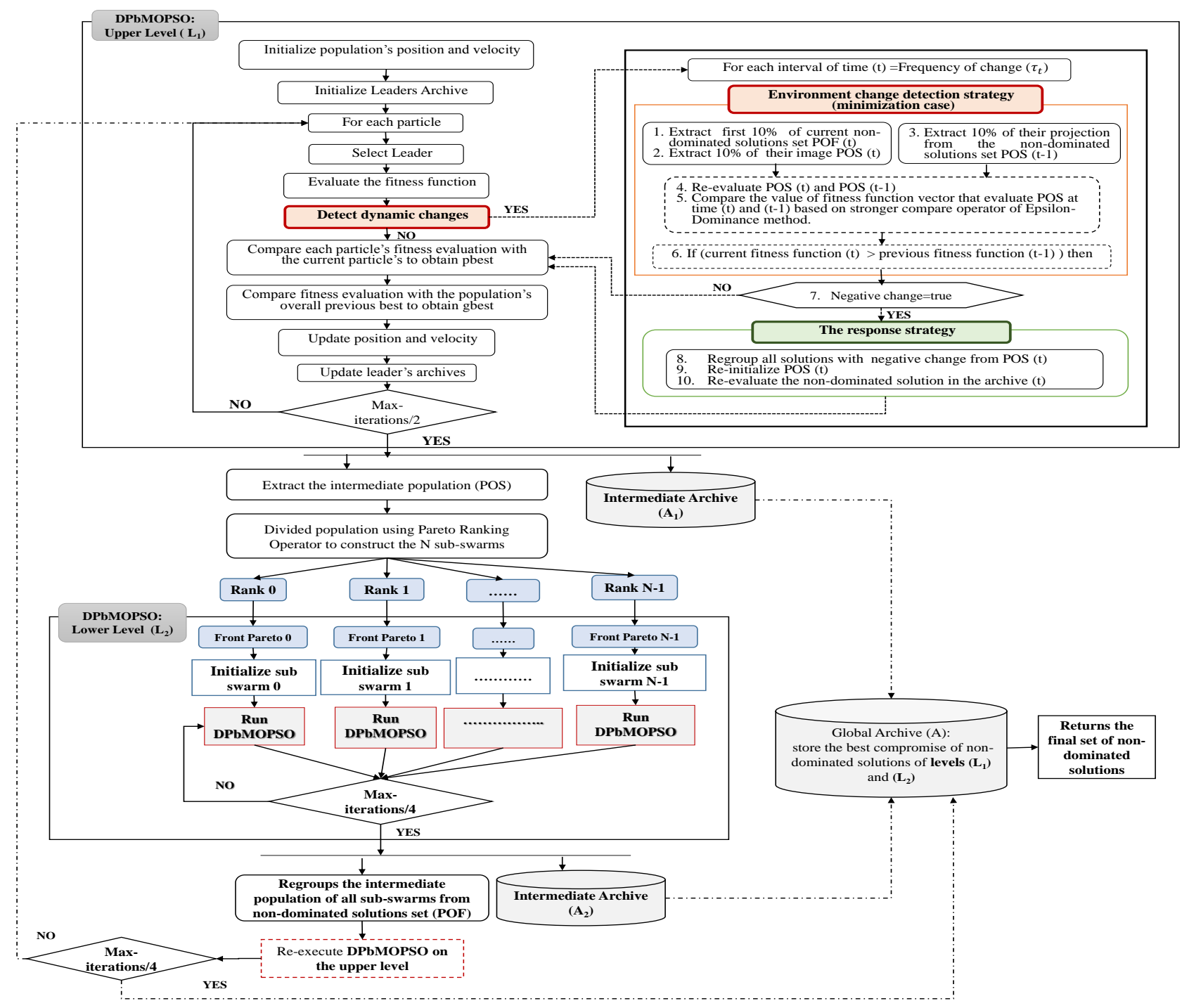

Fig. 1: The Proposed Dynamic Pareto bi-level Multi-Objective Particle Swarm Optimization (DPb-MOPSO)

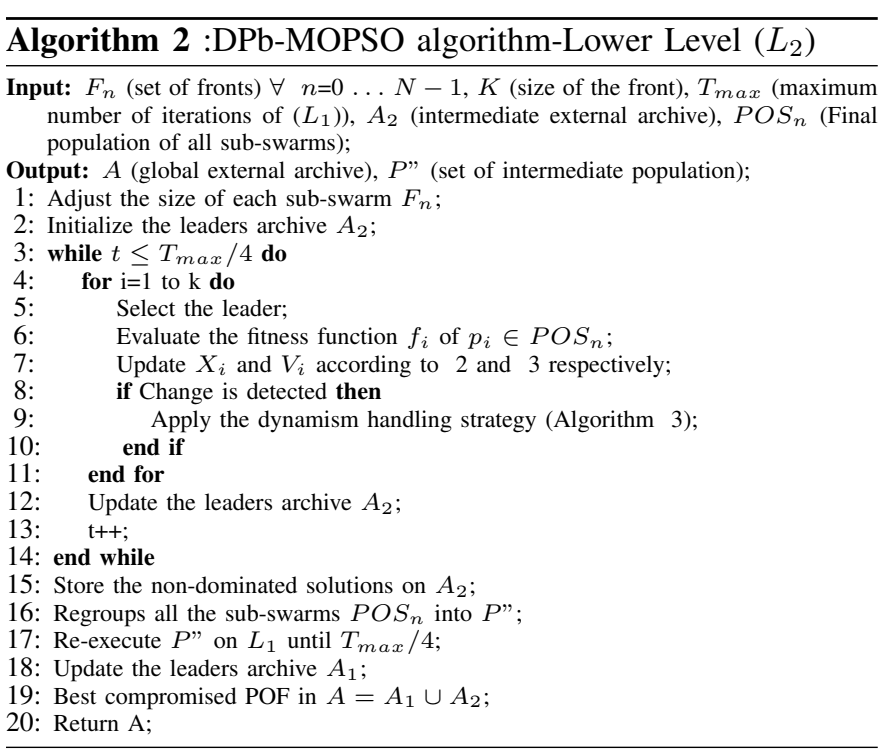

until $25 \%$ of $T_{\max }$. When achieving $T_{\max }$, all the nondominated solutions from both $A_{1}$ and $A_{2}$ are regrouped in the global archive $A$ using Epsilon dominance operator.

\section{Dynamism Handling Strategy}

Filling the gap for ensuring convergence during the run that may cause a lack of diversity in a dynamic environment. Two steps for dynamism handling strategy are considered in Algorithm 3 and detailed as follows:

\section{- Step 1: Environment detection strategy}

The environmental change is checked at the frequency $\tau_{t}$, which is equal to 5,10 , and 20 for severe, moderate, and slight environmental changes respectively. The comparison procedure is started after the evaluation of fitness function $F_{i}$ by selecting $10 \%$ of previous $P O F(t-1)$ and current $P O F(t)$ as detectors; then, we select $10 \%$ of their mapped POS $(t-1)$ and $P O S(t)$ for controlling their evolution over time. The strong dominance operator of Epsilon-Dominance method is used to compare dynamic behavior of particles between 


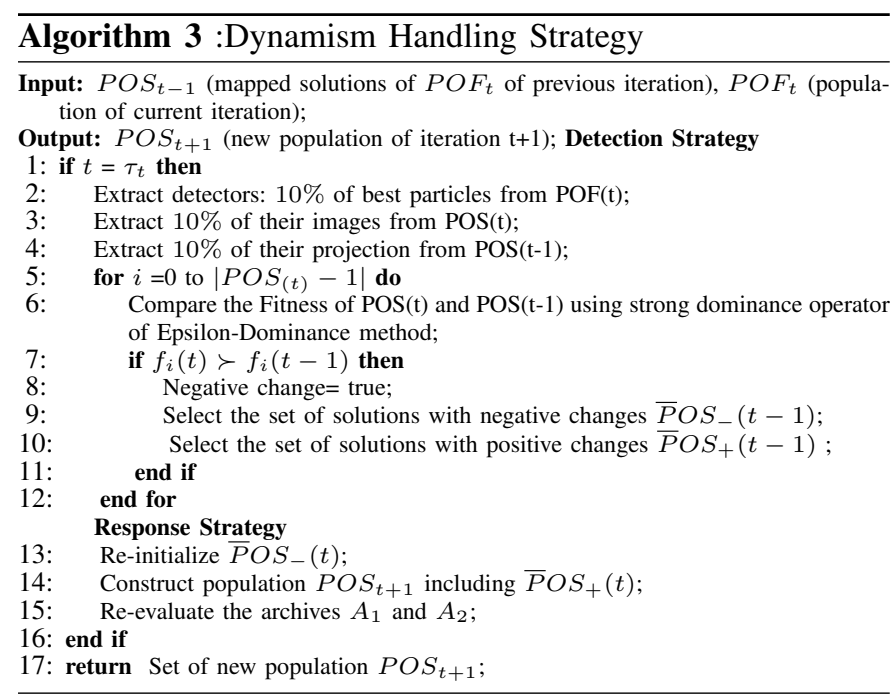

$\operatorname{POS}(t-1)$ and $\operatorname{POS}(t)$. A solution $X_{t}$ strongly dominates the solution $X_{t-1}$ if $X_{t}$ is strictly better $\left(X_{t} \succ X_{t-1}\right)$ than $X_{t-1}$ for all $M$ objectives.

\section{- Step 2: Response change strategy}

If a change is identified successfully, the DPb-MOPSO adapts all solutions with negative changes $P O S_{-}(t)$ to be reinitialized and all detectors with positive changes $\mathrm{POS}_{+}(t)$ are integrated in the new population to ensure good diversity and convergence using only solutions with positive effects. Also, the leader's archive is re-evaluated to update all nondominated solutions and overcome the deterioration of the research ability.

\section{EXPERIMENTAL STUdy: PRELIMINARIES}

In this section, we aim to present the evolutionary algorithms, the DMOPs and the quality indicators considered for this case study. The empirical study was discussed referring to the contribution of Jiang et al. [13].

\section{A. Evolutionary and Swarm Intelligence Multi-Objective Al- gorithms}

Our main case of study consists of the comparison of performance between the proposed $\mathrm{DPb}-\mathrm{MOPSO}$ and several algorithms regrouped as follow:

- The five static optimization methods considered for DMOPs namely;

- The dCOEA [8] defined as a hybrid competitive and cooperative method adapts an additional archive to save the outdated individuals to assess the new optimization step.

- The MOEA/D [31] presenting a decompositionbased approach aiming to replace a limited number of individuals with any new created solutions.

- The dMOPSO [18] is a decomposition PSO-based approach used for static MOPs.

- The MOPSO [5] is the standard version of PSO designed for static MOPs.

- The pbMOPSO [7] is the MOPSO-based approach using a distributed architecture for static MOPs.
- The two diversity based approaches:

- The DNSGA-II [14] using a randomly created or mutated individuals after the change.

- The Dynamic-MOPSO [2] presenting a dynamic version of the standard MOPSO approach with a dynamism handling strategy for solving DMOPs in type I.

- The prediction-based approach PPS [34] using a univariate auto-regression model to predict the new location of POS.

- The memory-based approach SGEA [13] aiming to reuse some outdated solutions with good distribution to relocate solutions closer to the new POF.

All algorithms are executed during 30 independent runs for each DMOPs. Each run is stopped when the maximum number of evaluations $T_{\max }$ is achieved using $\left(3 \times n_{t} \times \tau_{t}+50\right)$. Where, $\tau_{t}$ is the frequency of changes fixed to 5, 10 and 20 respectively, and $n_{t}$ is the severity of changes fixed to 10 . All experimental settings are summarized in Table II.

\section{TABLE II: Parameters Settings of MOEAs}

\begin{tabular}{|c|c|}
\hline \multicolumn{2}{|c|}{ Common parameters of MOPSO-based Algorithms } \\
\hline Perturbation index & 20 \\
\hline Mutation probability & $1.0 /$ number of problems' variables \\
\hline $\begin{array}{l}\text { Acceleration Coefficients }(\mathrm{c} 1, \mathrm{c} 2) \\
\text { Inertia weight }(\mathrm{w})\end{array}$ & $\begin{array}{l}\mathrm{c} 1=\mathrm{c} 1=\text { rand }(1.5,2.0) \\
\text { rand }(0.1,0.4)\end{array}$ \\
\hline Common parameters of dCOEA, & PPS, MOEAD, SGEA and DNSGA-II \\
\hline \begin{tabular}{|l|} 
Crossover Probability \\
\end{tabular} & 1.0 \\
\hline Mutation Distribution Index & 20 \\
\hline Crossover Distribution Index & 20 \\
\hline \multicolumn{2}{|c|}{\begin{tabular}{|c|} 
Common parameters for all algorithms \\
\end{tabular}} \\
\hline Swarm size & 100 \\
\hline Archive size & 100 \\
\hline Max iteration & $3 \times n_{t} \times \tau_{t}+50$ \\
\hline Independent runs & $30-2-2$ \\
\hline
\end{tabular}

\section{B. Dynamic Multi Objective Problems}

Twenty-one DMOPs [13], [27] are used for algorithms testing. Table III presenting all parameter settings and the changed nature of POS and POF.

\section{Quality Indicators}

The Inverted Generational Distance (IGD) and the Hypervolume Difference (HVD) are used to measure both of convergence and diversity considering the smaller values as the best. The IGD is computed using 4 based on the minimum euclidean distance $d_{i}$ between ith points in the generated $n P O F(|P O F|)$ and the true $P O F^{*}$. In addition, the HVD is calculated using 5 to measure the difference between the obtained $P O F$ to the true $P O F^{*}$.

$$
\begin{gathered}
I G D=\frac{1}{n P O F} \sum_{i=1}^{n P O F} d_{i} \\
H V D=H V(P O F)-H V\left(P O F^{*}\right)
\end{gathered}
$$

\section{ExPERIMENTAL Results AND StatisticAl AnAlysis}

The concepts of inferential statistics over Friedman twoway Analysis of Variance (Friedman two-way ANOVA) is devoted to discussing all Mean (M.) and Standard Deviation 
TABLE III: Parameter settings and dynamic characteristics of DMOPs

\begin{tabular}{|c|c|c|c|c|c|c|c|}
\hline \multirow{2}{*}{\multicolumn{2}{|c|}{ DMOPs }} & \multirow{2}{*}{ Nb. Obj. } & \multirow{2}{*}{ Nb. Var. } & \multirow{2}{*}{ Type } & \multirow{2}{*}{ POS Change Nature } & \multicolumn{2}{|c|}{ POF Change Nature } \\
\hline & & & & & & Shift & $\begin{array}{r}\text { Curvature } \\
\end{array}$ \\
\hline \multirow{5}{*}{$\begin{array}{l}\text { FDA problems } \\
\text { Farina et al. }\end{array}$} & FDA1 & 2 & 20 & II & \multirow{5}{*}{ Sinusoidal change + Vertical shift } & No change & No change +Convex \\
\hline & FDA2 & 2 & 15 & III & & Vertical + Density of solutions change & Change from convex to concave \\
\hline & FDA3 & 2 & 30 & II & & Vertical + Density of solutions change & Change + Convex \\
\hline & FDA4 & 3 & 12 & I & & No change + Spread of solutions change & No change + Concave \\
\hline & FDA5 & 3 & 12 & III & & Radius variations + Density of solutions change & Change + Concave \\
\hline \multirow{3}{*}{$\begin{array}{l}\text { dMOP problems } \\
\text { Goh et al. }[8]\end{array}$} & dMOP1 & 2 & 10 & IIII & No change & Vertical & Change from convex to concave \\
\hline & dMOP2 & 2 & 10 & II & \multirow{2}{*}{$\begin{array}{l}\text { Sinusoidal change + Vertical shift } \\
\text { Sinusoidal change + Vertical shift }\end{array}$} & Vertical & Change from convex to concave \\
\hline & $\mathrm{dMOP} 3$ & 2 & 10 & I & & No change & No change + Convex \\
\hline \multirow{6}{*}{$\begin{array}{l}\text { ZJZ problems } \\
\text { Zhou et al. }[34]\end{array}$} & F5 & 2 & 20 & III & \multirow{6}{*}{ Vertical shift } & \multirow{6}{*}{ Vertical } & \multirow{6}{*}{ Change from convex to concave } \\
\hline & F6 & 2 & 20 & III & & & \\
\hline & F7 & 2 & 20 & III & & & \\
\hline & F8 & 3 & 20 & II & & & \\
\hline & F9 & 2 & 20 & III & & & \\
\hline & F10 & 2 & 20 & III & & & \\
\hline \multirow{7}{*}{$\begin{array}{l}\text { UDF problems } \\
\text { Biswas et al. }\end{array}$} & UDF1 & 2 & 10 & I & Vertical shift & Diagonal & No change \\
\hline & UDF2 & 2 & 10 & I & Vertical shift + curvature change & Vertical & No change \\
\hline & UDF3 & 2 & 10 & IIII & No variation & Diagonal & No change \\
\hline & UDF4 & 2 & 10 & III & Horizontal shift & No change & Angular shift + Change from convex to concave \\
\hline & UDF5 & 2 & 10 & II & Polynomial + Vertical shift & No change & Angular shift + Change from convex to concave \\
\hline & UDF6 & 2 & 10 & IIII & No variation & Diagonal & Angular shift \\
\hline & UDF7 & 3 & 10 & IIII & No variation & Radial+shift of the center & No change \\
\hline
\end{tabular}

(Std.) values showed in Tables VIII, IX, XII and XV. Previous analysis using only IGD and HVD metrics is insufficient to evaluate the performance of a swarm intelligence algorithms and highlight the significant level [12]. In this study, the ANOVA procedure is used and does not assume a normal distribution to compare multiple treatments and decide the significance level between algorithms.

\section{A. Procedure of Friedman two-way Analysis of Variance}

The Friedman two-way ANOVA test is done using the following steps :

- Step 1: the normality distribution test is done through the Q-Q plot for all algorithms over IGD and HVD metrics with both $\tau_{t}$ and $n_{t}$ are equal to 10 . Taking the example of Q-Q plot of DPb-MOPSO in Figure 2, the data-points does not fall the straight line of the ideal normal distribution curve and does not fit the normal distribution. However, due to the non-normality of data the Friedman two-way ANOVA by ranks is used as a nonparametric statistical procedure to decide the significance level between algorithms.
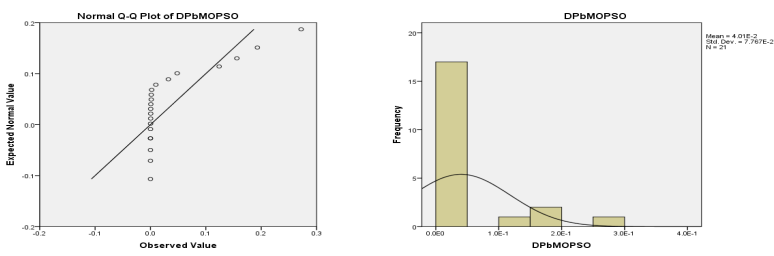

Fig. 2: DPb-MOPSO: Q-Q plot and histogram.

- Step 2: prepare the observation's matrix for all algorithms/problems pair.

- Step 3: define both null hypothesis $H_{0}$ (no difference between the mean values), and the alternative hypothesis $H_{1}$ (presents the difference).

- Step 4: state the significance level Alpha $(\alpha)$ to determine at which level the null hypothesis may be rejected. The $p-$ value helps us to estimate how significant the results of algorithms, and we reject the null hypothesis if $p$-value $\leq \alpha$; where $\alpha=0.05 . H_{0}: \mu_{1}=\mu_{i}$ (all treatment effects are zero) and $H_{1}: \mu_{1} \neq \mu_{i}$ (not all treatment effects are zero).

- Step 5: determine the degree of freedom ( $\mathrm{df}=\mathrm{k}-1)$, where $\mathrm{k}$ is the number of algorithms equal to 10 , the $\mathrm{df}$ is equal to 9 .

- Step 6: state the decision rule, according to nine degree of freedom and $\alpha=0.05$ is defined following to the ChiSquare $\left(\chi^{2}\right)$ table ${ }^{1}$. The critical value (CV) is equal to 16.92 , if the computed $\chi^{2}$ greater than $\mathrm{CV}$ we're going to reject the null hypothesis $H_{0}$.

- Step 7: Friedman two-way ANOVA by ranks is considered as follows:

1) Assign the rank values $\left(r_{i j}\right)$ for each problem $i$ while; 1 is the best result to $k$ which is the worst result (where; $1 \leq i \leq P$ and $1 \leq j \leq k$ ) and for the ties cases, we assign the average of ranks.

2) Compute the average of ranks obtained for each algorithm/problem pair using 6 .

$$
R_{j}=\frac{1}{n} \sum_{i} r_{j}^{i}
$$

3) Hypothesis testing, to retain null hypothesis the Friedman statistic $F_{f}$ is computed according to 7 based on the probability distribution $\chi^{2}$ with nine degree of freedom.

$$
F_{f}=\frac{12 n}{k(k+1)}\left[\sum_{i} R_{j}^{2}-\frac{k(k+1)^{2}}{4}\right] .
$$

In most of the cases, the Friedman ranking test assumed the assumption of ignoring the null hypothesis implies that at least two algorithms differ in significance. The Friedman ranks and their $p$-value can not define where the algorithm variance is which leads to the Friedman $1 \times N$ ANOVA multiple comparisons with the DPb-MOPSO is the control method using different Post-hoc procedures [12] described in step 8.

\footnotetext{
${ }^{1}$ http://kisi.deu.edu.tr/joshua.cowley/Chi-square-table.pdf
} 
- Step 8: The Post-hoc procedures are classified in Table IV aiming to compute the Adjusted P-Value (APV) and identify the significant level of variation between algorithms.

TABLE IV: Post-hoc procedures for $1 \times N$ comparisons

\begin{tabular}{|l|l|l|}
\hline \multicolumn{1}{|c|}{ Classes } & \multicolumn{1}{|c|}{ Procedures } & \multicolumn{1}{c|}{ Adjusted P-Value (APV) } \\
\hline One-step & Bonferroni_Dunn & $\begin{array}{l}\min \{\mathrm{v}, 1\} ; \text { where } \mathrm{v}=(\mathrm{K}-1) p_{i} \\
\mathrm{k}: \text { number of tested algorithms and } \mathrm{i} \in 1, \cdots, \mathrm{K} .\end{array}$ \\
\hline Step-down & $\mathrm{Holm}$ & $\min \{\mathrm{v}, 1\} ;$ where $\mathrm{v}=\max (\mathrm{k}-1) p_{j}: 1 \leq \mathrm{j} \leq \mathrm{i}$ \\
\hline Step-up & Hochberg & $\max (\mathrm{k}-\mathrm{j}) p_{j}: \mathrm{k}-1 \geq \mathrm{j} \geq \mathrm{i}$. \\
\hline Two-step & $\mathrm{Li}$ & $p_{i} /\left(p_{i}+1-p_{k-1}\right)$. \\
\hline
\end{tabular}

\section{B. Results Analysis through Friedman two-way ANOVA Test}

Different configurations are considered on MOEAs to demonstrate the impact of the frequency of the change for solving problems with the different nature of changes in the POS and POF. Those configurations are achieved according to the constant value of the severity of change $n_{t}$ set to 10 and the variation of the frequency $\tau_{t}$ from 5,10 to 20 representing severe, moderate and slight environmental changes respectively. All significant results are reported in Tables VIII, IX, XII and XV and highlighted in bold faces for twenty one problems $(P=21)$ considering five FDA, three dMOP, six F(ZJZ) and seven UDF functions per algorithm $K$ is equal to ten $(K=10)$. We can conclude that the five MOPSObased algorithms (dMOPSO, MOPSO, pbMOPSO, DynamicMOPSO and DPb-MOPSO) are the most competitive methods over both IGD and HVD metrics. The mean values are not very useful to confirm whether the new proposed DPb-MOPSO has significant improvement compared to other algorithms. For that reason, three groups of analysis are considered for the Friedman two-way ANOVA ranking test and the Post-hoc procedures:

- Friedman two-way ANOVA test for moderate environmental changes $\left(\tau_{t}=n_{t}=10\right)$.

- Friedman two-way ANOVA test for severe environmental changes $\left(\tau_{t}=5\right.$ and $\left.n_{t}=10\right)$.

- Friedman two-way ANOVA test for slight environmental changes $\left(\tau_{t}=20\right.$ and $\left.n_{t}=10\right)$.

1) Friedman rankings test: let's first consider the Friedman two-way ANOVA by ranks over a group of twenty one problems with moderate environmental changes. The average rankings are obtained over IGD and HVD metrics assigning to the best algorithm the ranking one and to the worst the ranking $k$. Under the null hypothesis, the test statistics of the Chi-Square $\left(\chi^{2}\right)$ distribution with nine degrees of freedom and the p-value are computed. Based on Table V, we can conclude that the DPb-MOPSO has the best ranks compared to other algorithms. In addition, the proposed DPb-MOPSO is the winner for solving the group of eight problems (5 FDA and 3 dMOP functions) with severe environmental changes such as demonstrated on Table VI. Besides, Table VII presents the average rankings for slight environmental changes while the DPb-MOPSO has the best rank over IGD and fail over HVD compared to MOPSO algorithm. Whereas, all computed $\chi^{2} \geq 16.92$ assuming the existence of significant difference between all algorithms. Friedman's ranking test detects the significant difference over the whole multiple comparison and cannot be able to detect when one method performed better than the other. This issue leads to the Friedman $1 \times N$ ANOVA multiple comparisons with the DPb-MOPSO is the control method using four Post-hoc comparisons procedures such as resuming in Table IV and detailed in the following subsection.

TABLE V: Friedman average rankings over HVD and IGD metrics with $\tau_{t}=n_{t}=10$ for FDA, dMOP, F(ZJZ) and UDF.

\begin{tabular}{|l|c|c|}
\hline \multirow{2}{*}{ Algorithms } & \multicolumn{2}{|c|}{ Ranks } \\
\cline { 2 - 3 } & IGD & HVD \\
\hline DNSGA-II & 6.86 & 7.6 \\
dCOEA & 7.5 & 7.86 \\
PPS & 6.67 & 7.31 \\
MOEA/D & 7.31 & 7,98 \\
SGEA & 5.67 & 5.93 \\
MOPSO & 5.29 & 3.83 \\
dMOPSO & 6.21 & 3.57 \\
pbMOPSO & 4.38 & 4.21 \\
Dynamic-MOPSO & 3.6 & 4.1 \\
DPb-MOPSO & $\mathbf{1 . 5 2}$ & $\mathbf{2 . 6 2}$ \\
$\chi^{2}$ & 73.09 & 87.26 \\
p-value $(\alpha=0.05)$ & $3.78 \mathrm{E}-12$ & $5.76 \mathrm{E}-15$ \\
\hline
\end{tabular}

TABLE VI: Friedman average rankings over HVD and IGD metrics with $\tau_{t}=5$ and $n_{t}=10$ for FDA and dMOP.

\begin{tabular}{|l|c|c|}
\hline \multirow{2}{*}{ Algorithms } & \multicolumn{2}{|c|}{ Ranks } \\
\cline { 2 - 3 } & IGD & HVD \\
\hline DNSGA-II & 8.81 & 8.63 \\
dCOEA & 6.44 & 7.25 \\
PPS & 7.75 & 8.63 \\
MOEA/D & 8 & 9.13 \\
SGEA & 5.75 & 6.38 \\
MOPSO & 3.75 & 2.75 \\
dMOPSO & 5.38 & 2.75 \\
pbMOPSO & 3.38 & 3.38 \\
Dynamic-MOPSO & 3.13 & 3.5 \\
DPb-MOPSO & $\mathbf{2 . 6 3}$ & $\mathbf{2 . 3 6}$ \\
$\chi^{2}$ & 39.06 & 59.70 \\
p-value $(\alpha=0.05)$ & 0.000011 & $1.53 E-9$ \\
\hline
\end{tabular}

TABLE VII: Friedman average rankings over HVD and IGD metrics with $\tau_{t}=20$ and $n_{t}=10$ for FDA and dMOP.

\begin{tabular}{|l|c|c|}
\hline \multirow{2}{*}{ Algorithms } & \multicolumn{2}{|c|}{ Ranks } \\
\cline { 2 - 3 } & IGD & HVD \\
\hline DNSGA-II & 8.5 & 8.25 \\
dCOEA & 7.13 & 8.25 \\
PPS & 8 & 8.5 \\
MOEA/D & 7.5 & 8.5 \\
SGEA & 5.38 & 6.5 \\
MOPSO & 4.06 & $\mathbf{2 . 3 1}$ \\
dMOPSO & 5.81 & 2.56 \\
pbMOPSO & 4 & 3 \\
Dynamic-MOPSO & 2.5 & 4.13 \\
DPb-MOPSO & $\mathbf{2 . 1 3}$ & 3 \\
$\chi^{2}$ & 40.79 & 58.78 \\
p-value $(\alpha=0.05)$ & 0.000005 & $2.30 \mathrm{E}-9$ \\
\hline
\end{tabular}

2) Friedman $1 \times N$ ANOVA Multiple Comparisons: The 1 $\times \mathrm{N}$ comparisons are made to evaluate the studies of $\mathrm{k}-1$ algorithms and calculate the unadjusted and the adjusted $P$-Value (APV) for each hypothesis except DPb-MOPSO is the control method. The average rankings of all methods are transformed to the unadjusted $p$-value which is computed using the normal approximation. The test statistics are considered to compare the $i$ th algorithm with the $j$ th algorithm which are ordered from the smallest to the largest ranks (i). Applying the four Post-hoc procedures can then lead to the APV determining the 
TABLE VIII: Mean and Standard Deviation Values of all MOEAs over IGD and HVD Metrics for UDF with $\left(\tau_{t}=n_{t}=10\right)$.

\begin{tabular}{|c|c|c|c|c|c|c|c|c|c|c|c|}
\hline \multirow{2}{*}{ Prob. } & \multirow{2}{*}{ QI } & \multirow{2}{*}{\multicolumn{5}{|c|}{ Val. Tested Algorithms of Jiang et al. [13] }} & \multicolumn{5}{|c|}{ Additional Tested MOPSO based Algorithms } \\
\hline & & & & & MOEA/D & SGEA & MOPSO & dMOPSO & pbMOPSC & Dynamic- & DIDPb-MOPSO \\
\hline \multirow[b]{4}{*}{ UDF1 } & HVD & \begin{tabular}{|l|l|l|l} 
M. & $5.14 \mathrm{E}-1$ \\
\end{tabular} & $7.47 \mathrm{E}-1$ & $7.97 \mathrm{E}-1$ & $6.12 \mathrm{E}-1$ & $5.18 \mathrm{E}-1$ & $-2.99 \mathrm{E}+0$ & $-2.99 \mathrm{E}+0$ & $4.83 \mathrm{E}-3$ & $5.24 \mathrm{E}-3$ & $3.14 \mathrm{E}-4$ \\
\hline & $\mathrm{HVD}$ & Std. $3.2 \mathrm{E}-2$ & $3.8 \mathrm{E}-2$ & $5.2 \mathrm{E}-2$ & $9.4 \mathrm{E}-2$ & $5.0 \mathrm{E}-2$ & $1.2 \mathrm{E}-5$ & $1.1 \mathrm{E}-7$ & $4.5 \mathrm{E}-4$ & $1.1 \mathrm{E}-4$ & $6.1 \mathrm{E}-6$ \\
\hline & & \begin{tabular}{l|l} 
M. & $1.07 \mathrm{E}-1$
\end{tabular} & $2.91 \mathrm{E}-1$ & $2.67 \mathrm{E}-1$ & $1.70 \mathrm{E}-1$ & $1.24 \mathrm{E}-1$ & $5.52 \mathrm{E}-3$ & $5.52 \mathrm{E}-3$ & $1.70 \mathrm{E}-5$ & $1.72 \mathrm{E}-5$ & $1.14 \mathrm{E}-6$ \\
\hline & & Std. $2.4 \mathrm{E}-2$ & $2.3 \mathrm{E}-2$ & $2.2 \mathrm{E}-2$ & $5.1 \mathrm{E}-2$ & $3.3 \mathrm{E}-2$ & $8.2 \mathrm{E}-11$ & $1.0 \mathrm{E}-10$ & $1.2 \mathrm{E}-6$ & $4.4 \mathrm{E}-7$ & $1.8 \mathrm{E}-8$ \\
\hline \multirow[b]{4}{*}{ UDF2 } & & \begin{tabular}{l|l} 
M. & $5.51 \mathrm{E}-1$
\end{tabular} & $6.13 \mathrm{E}-1$ & $4.32 \mathrm{E}-1$ & $5.42 \mathrm{E}-1$ & $5.10 \mathrm{E}-1$ & $-2.99 \mathrm{E}+0$ & $-2.99 \mathrm{E}+0$ & $4.84 \mathrm{E}-3$ & $5.21 \mathrm{E}-3$ & $3.16 \mathrm{E}-4$ \\
\hline & & Std. $2.4 \mathrm{E}-2$ & $2.8 \mathrm{E}-2$ & $1.9 \mathrm{E}-2$ & $1.7 \mathrm{E}-2$ & $2.5 \mathrm{E}-2$ & $9.5 \mathrm{E}-6$ & $1.1 \mathrm{E}-7$ & 3.2E-4 & 7.2E-5 & $8.2 \mathrm{E}-6$ \\
\hline & & M. $1.12 \mathrm{E}-1$ & $1.83 \mathrm{E}-1$ & $2.54 \mathrm{E}-2$ & $1.16 \mathrm{E}-1$ & $8.95 \mathrm{E}-2$ & $5.53 \mathrm{E}-3$ & $5.53 \mathrm{E}-3$ & $1.71 \mathrm{E}-5$ & $1.70 \mathrm{E}-5$ & $1.14 \mathrm{E}-6$ \\
\hline & IUD & Std. $1.0 \mathrm{E}-2$ & $2.0 \mathrm{E}-2$ & $5.0 \mathrm{E}-3$ & $9.5 \mathrm{E}-3$ & $1.3 \mathrm{E}-2$ & $1.6 \mathrm{E}-10$ & $0.0 \mathrm{E}+0$ & $8.1 \mathrm{E}-7$ & $2.1 \mathrm{E}-7$ & $2.2 \mathrm{E}-8$ \\
\hline & & \begin{tabular}{|l|l|} 
M. & $1.22 \mathrm{E}+0$ \\
\end{tabular} & $1.23 \mathrm{E}+0$ & $1.73 \mathrm{E}+0$ & $1.22 \mathrm{E}+0$ & $1.22 \mathrm{E}+0$ & $5.05 \mathrm{E}-3$ & $5.04 \mathrm{E}-3$ & $4.85 \mathrm{E}-3$ & $5.05 \mathrm{E}-3$ & 3.08E-4 \\
\hline & & Std. $1.9 \mathrm{E}-3$ & 7.0E-2 & $3.1 \mathrm{E}-4$ & $2.4 \mathrm{E}-3$ & $2.4 \mathrm{E}-3$ & $1.4 \mathrm{E}-5$ & $1.1 \mathrm{E}-7$ & 3.0E-4 & $8.9 \mathrm{E}-6$ & $5.5 \mathrm{E}-6$ \\
\hline & & \begin{tabular}{l|l} 
M. & $6.06 \mathrm{E}-1$
\end{tabular} & $6.51 \mathrm{E}-1$ & $4.55 \mathrm{E}+0$ & $6.06 \mathrm{E}-1$ & $6.06 \mathrm{E}-1$ & $1.52 \mathrm{E}-5$ & $1.48 \mathrm{E}-5$ & $1.59 \mathrm{E}-5$ & $1.51 \mathrm{E}-5$ & $1.04 \mathrm{E}-6$ \\
\hline \multirow[t]{3}{*}{ UDF3 ${ }^{1}$} & & Std. $3.3 \mathrm{E}-6$ & $7.7 \mathrm{E}-2$ & $1.1 \mathrm{E}+0$ & $6.3 \mathrm{E}-5$ & 7.4E-6 & $8.1 \mathrm{E}-8$ & $5.6 \mathrm{E}-10$ & $1.0 \mathrm{E}-6$ & $6.9 \mathrm{E}-8$ & $1.7 \mathrm{E}-8$ \\
\hline & & \begin{tabular}{|l|l} 
M. & $3.47 \mathrm{E}-1$ \\
\end{tabular} & $5.06 \mathrm{E}-1$ & $3.77 \mathrm{E}-1$ & $6.41 \mathrm{E}-1$ & $3.32 \mathrm{E}-1$ & $-2.44 \mathrm{E}-2$ & $-2.39 \mathrm{E}-2$ & $8.65 \mathrm{E}-4$ & $7.10 \mathrm{E}-3$ & $2.92 \mathrm{E}-4$ \\
\hline & & Std. $8.3 \mathrm{E}-2$ & 3.7E-2 & $2.1 \mathrm{E}-2$ & $1.9 \mathrm{E}-1$ & 7.1E-2 & $1.8 \mathrm{E}-5$ & 1.6E-7 & $5.8 \mathrm{E}-4$ & $2.3 \mathrm{E}-4$ & $9.0 \mathrm{E}-6$ \\
\hline \multirow[b]{2}{*}{ UDF $4^{1}$} & & \begin{tabular}{l|l} 
M. & $1.70 \mathrm{E}-1$ \\
\end{tabular} & $2.87 \mathrm{E}-1$ & $1.85 \mathrm{E}-1$ & $3.19 \mathrm{E}-1$ & $1.68 \mathrm{E}-1$ & $8.18 \mathrm{E}-5$ & $8.18 \mathrm{E}-5$ & $1.35 \mathrm{E}-5$ & $1.42 \mathrm{E}-5$ & $1.01 \mathrm{E}-6$ \\
\hline & & Std. $4.7 \mathrm{E}-2$ & $2.8 \mathrm{E}-2$ & $8.2 \mathrm{E}-3$ & $1.3 \mathrm{E}-1$ & $4.4 \mathrm{E}-2$ & $2.1 \mathrm{E}-8$ & $1.8 \mathrm{E}-10$ & $6.2 \mathrm{E}-7$ & $1.8 \mathrm{E}-7$ & $2.1 \mathrm{E}-8$ \\
\hline \multirow{4}{*}{$\begin{array}{l}\text { UDF5 } \\
\text { UDF }\end{array}$} & & \begin{tabular}{l|l} 
M. & $2.78 \mathrm{E}-1$
\end{tabular} & $3.98 \mathrm{E}-1$ & $2.70 \mathrm{E}-1$ & $3.65 \mathrm{E}-1$ & $2.72 \mathrm{E}-1$ & $|-2.44 \mathrm{E}-2|$ & $-2.39 \mathrm{E}-2$ & $8.53 \mathrm{E}-4$ & 7.12E-3 & $2.92 \mathrm{E}-4$ \\
\hline & & Std. $2.5 \mathrm{E}-2$ & 3.3E-2 & $1.5 \mathrm{E}-2$ & $2.7 \mathrm{E}-2$ & $1.8 \mathrm{E}-2$ & $1.7 \mathrm{E}-5$ & $1.5 \mathrm{E}-7$ & $3.9 \mathrm{E}-4$ & $1.6 \mathrm{E}-4$ & $1.1 \mathrm{E}-5$ \\
\hline & & \begin{tabular}{l|l} 
M. & $1.18 \mathrm{E}-1$ \\
\end{tabular} & $2.05 \mathrm{E}-1$ & $2.89 \mathrm{E}-2$ & $1.61 \mathrm{E}-1$ & $1.00 \mathrm{E}-1$ & $8.21 \mathrm{E}-5$ & $8.21 \mathrm{E}-5$ & $1.37 \mathrm{E}-5$ & $1.42 \mathrm{E}-5$ & $1.02 \mathrm{E}-6$ \\
\hline & & Std. $1.2 \mathrm{E}-2$ & 3.5E-2 & $1.3 \mathrm{E}-2$ & $1.4 \mathrm{E}-2$ & $1.1 \mathrm{E}-2$ & $1.6 \mathrm{E}-8$ & 2.0E-10 & $6.3 \mathrm{E}-7$ & $1.4 \mathrm{E}-7$ & 2.3E-8 \\
\hline \multirow{4}{*}{ UDF6 } & & \begin{tabular}{l|l} 
M. & $9.34 \mathrm{E}-1$
\end{tabular} & $1.26 \mathrm{E}+0$ & $1.83 \mathrm{E}+0$ & $1.21 \mathrm{E}+0$ & $9.77 \mathrm{E}-1$ & $-3.96 \mathrm{E}+2$ & $2-3.99 \mathrm{E}+2$ & $-2.07 \mathrm{E}-2$ & $-7.85 \mathrm{E}-3$ & $-2.68 \mathrm{E}-2$ \\
\hline & HVD & Std. $1.5 \mathrm{E}-1$ & $7.2 \mathrm{E}-2$ & $1.0 \mathrm{E}-2$ & $1.4 \mathrm{E}-1$ & $2.0 \mathrm{E}-1$ & $6.7 \mathrm{E}-3$ & 3.6E-2 & $2.3 \mathrm{E}-2$ & 3.6E-3 & 2.6E-2 \\
\hline & & \begin{tabular}{|l|l} 
M. & $4.57 \mathrm{E}-1$ \\
\end{tabular} & $8.04 \mathrm{E}-1$ & $1.34 \mathrm{E}+0$ & $5.31 \mathrm{E}-1$ & $6.68 \mathrm{E}-1$ & $2.88 \mathrm{E}+0$ & $2.88 \mathrm{E}+0$ & $2.05 \mathrm{E}-3$ & $4.41 \mathrm{E}-4$ & $2.19 \mathrm{E}-3$ \\
\hline & & Std. $8.7 \mathrm{E}-2$ & $1.0 \mathrm{E}-1$ & $7.1 \mathrm{E}-2$ & $1.6 \mathrm{E}-1$ & $2.0 \mathrm{E}-1$ & 2.3E-6 & $1.8 \mathrm{E}-6$ & $4.8 \mathrm{E}-4$ & $9.6 \mathrm{E}-5$ & $4.3 \mathrm{E}-4$ \\
\hline \multirow[b]{4}{*}{ UDF7 } & & M. $2.40 \mathrm{E}+0$ & $1.91 \mathrm{E}+0$ & $2.06 \mathrm{E}+0$ & $2.32 \mathrm{E}+0$ & $2.06 \mathrm{E}+0$ & $4.62 \mathrm{E}+0$ & $-1.57 \mathrm{E}+1$ & -8.36E-1 & $-2.97 \mathrm{E}-1$ & $-2.08 \mathrm{E}+0$ \\
\hline & & Std. $7.4 \mathrm{E}-2$ & $1.7 \mathrm{E}-1$ & $5.4 \mathrm{E}-2$ & $2.4 \mathrm{E}-1$ & $1.2 \mathrm{E}-1$ & $3.0 \mathrm{E}-2$ & 5.6E-1 & $2.1 \mathrm{E}+0$ & $3.5 \mathrm{E}-1$ & $2.4 \mathrm{E}+0$ \\
\hline & & \begin{tabular}{|l|l} 
M. & $5.24 \mathrm{E}-1$ \\
\end{tabular} & $8.40 \mathrm{E}-1$ & $6.68 \mathrm{E}-1$ & $5.08 \mathrm{E}-1$ & $5.08 \mathrm{E}-1$ & $3.73 \mathrm{E}-1$ & $3.81 \mathrm{E}-1$ & $6.94 \mathrm{E}-4$ & $7.42 \mathrm{E}-4$ & $3.59 \mathrm{E}-4$ \\
\hline & & Std. $2.2 \mathrm{E}-2$ & $6.4 \mathrm{E}-2$ & $4.4 \mathrm{E}-2$ & $1.4 \mathrm{E}-1$ & $4.2 \mathrm{E}-2$ & $2.3 \mathrm{E}-6$ & 7.7E-3 & $7.5 \mathrm{E}-5$ & $5.9 \mathrm{E}-5$ & $1.9 \mathrm{E}-5$ \\
\hline
\end{tabular}

TABLE IX: Mean and Standard Deviation Values of all MOEAs over IGD and HVD Metrics for F (ZJZ) with $\left(\tau_{t}=n_{t}=10\right)$.

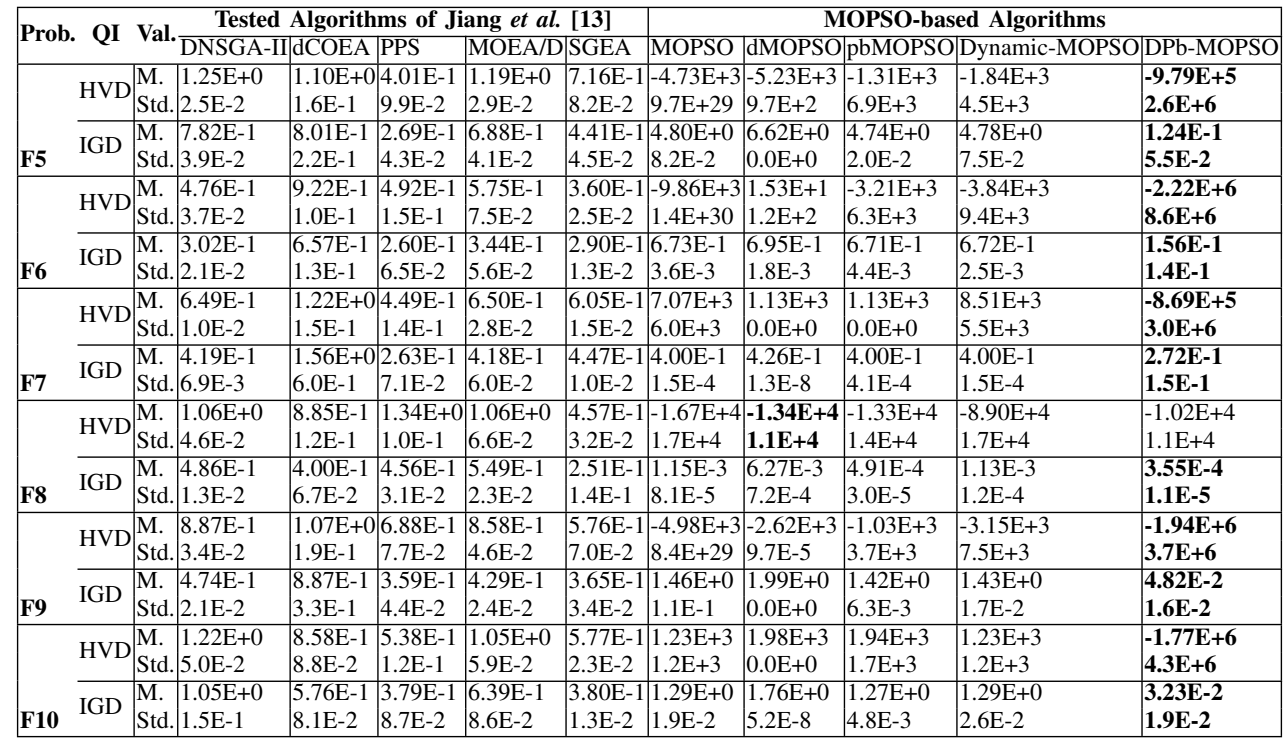

TABLE X: Adjusted p-values over IGD for twenty one problems with $\tau_{t}$ and $n_{t}$ are equal to 10 while DPb-MOPSO is the control method, $\alpha=0.05$.

\begin{tabular}{|c|c|c|c|c|c|c|}
\hline $\mathrm{i}$ & DPb-MOPSO vs. & unadjusted $p$ & $p_{\text {Bonf }}$ & $p_{\text {Holm }}$ & $p_{\text {Hochberg }}$ & $p_{L i}$ \\
\hline 1 & dCOEA & 0 & 0 & 0 & 0 & 0 \\
2 & MOEAD & 0 & 0 & 0 & 0 & 0 \\
3 & DNSGAII & 0 & 0 & 0 & 0 & 0 \\
4 & PPS & 0 & 0 & 0 & 0 & 0 \\
5 & dMOPSO & 0.000001 & 0.000005 & 0.000003 & 0.000003 & 0.000001 \\
6 & SGEA & 0.000009 & 0.000083 & 0.000037 & 0.000037 & 0.00001 \\
7 & MOPSO & 0.000057 & 0.00051 & 0.00017 & 0.00017 & 0.000058 \\
8 & pbMOPSO & 0.002229 & 0.020062 & 0.004458 & 0.004458 & 0.002285 \\
9 & Dynamic-MOPSO & 0.026625 & 0.239629 & 0.026625 & 0.026625 & 0.026625 \\
\hline
\end{tabular}

degree of rejection of the null hypothesis at 0.05 significance level taking into account the issues of Type I error (rejecting
TABLE XI: Adjusted p-values over HVD for twenty one problems with $\tau_{t}$ and $n_{t}$ are equal to 10 while DPb-MOPSO is the control method, $\alpha=0.05$.

\begin{tabular}{|c|c|c|c|c|c|c|}
\hline $\mathrm{i}$ & DPb-MOPSO vs. & unadjusted $p$ & $p_{\text {Bonf }}$ & $p_{\text {Holm }}$ & $p_{\text {Hochberg }}$ & $p_{L i}$ \\
\hline 1 & MOEAD & 0 & 0 & 0 & 0 & 0 \\
2 & dCOEA & 0 & 0 & 0 & 0 & 0 \\
3 & DNSGAII & 0 & 0.000001 & 0.000001 & 0.000001 & 0 \\
4 & PPS & 0.000001 & 0.000005 & 0.000003 & 0.000003 & 0.000001 \\
5 & SGEA & 0.000397 & 0.003573 & 0.001985 & 0.001985 & 0.000573 \\
6 & pbMOPSO & 0.087763 & 0.789867 & 0.351052 & 0.308063 & 0.11256 \\
7 & Dynamic-MOPSO & 0.114128 & 1.027155 & 0.351052 & 0.308063 & 0.141587 \\
8 & MOPSO & 0.193738 & 1.743642 & 0.387476 & 0.308063 & 0.218746 \\
9 & dMOPSO & 0.308063 & 2.772569 & 0.387476 & 0.308063 & 0.308063 \\
\hline
\end{tabular}

a true null hypothesis) [12].

Table X presents the APV over IGD metric for all tested 
TABLE XII: Mean and Standard Deviation Values of all MOEAs over IGD Metric for FDA and dMOP.

\begin{tabular}{|c|c|c|c|c|c|c|c|c|c|c|c|c|}
\hline \multirow{2}{*}{ Prob. } & \multirow{2}{*}{$\left(\tau_{t}, n_{t}\right)$} & \multirow{2}{*}{ Values } & \multicolumn{5}{|c|}{ Tested Algorithms of Jiang et al. [13] } & \multicolumn{5}{|c|}{ MOPSO-based Algorithms } \\
\hline & & & DNSGA- & I dCCOEA & PPS & MOEA/D & SGEA & MOPSO & dMOPSC & pbMOPS & Dynamic-MOPSO & DPb-MOPSO \\
\hline \multirow{6}{*}{ FDA1 } & \multirow{2}{*}{$(5,10)$} & M. & $6.40 \mathrm{E}-1$ & $6.36 \mathrm{E}-2$ & $2.08 \mathrm{E}-1$ & $3.56 \mathrm{E}-1$ & $3.41 \mathrm{E}-2$ & $26.05 E-5$ & $1.68 \mathrm{E}-4$ & $3.75 \mathrm{E}-3$ & $2.67 \mathrm{E}-3$ & $1.78 \mathrm{E}-3$ \\
\hline & & Std. & $9.8 \mathrm{E}-2$ & $1.1 \mathrm{E}-2$ & $8.4 \mathrm{E}-2$ & $4.9 \mathrm{E}-2$ & $8.0 \mathrm{E}-3$ & $2.0 \mathrm{E}-6$ & $8.8 \mathrm{E}-6$ & $4.0 \mathrm{E}-3$ & $2.4 \mathrm{E}-3$ & $4.3 \mathrm{E}-4$ \\
\hline & \multirow{2}{*}{$(10,10)$} & M. & $5.82 \mathrm{E}-2$ & $4.13 \mathrm{E}-2$ & $4.27 \mathrm{E}-2$ & $1.21 \mathrm{E}-1$ & $1.48 \mathrm{E}-2$ & $25.19 \mathrm{E}-5$ & $1.45 \mathrm{E}-4$ & $3.15 \mathrm{E}-3$ & $5.30 \mathrm{E}-4$ & $3.21 \mathrm{E}-4$ \\
\hline & & Std. & $3.8 \mathrm{E}-3$ & $6.5 \mathrm{E}-3$ & $1.9 \mathrm{E}-2$ & $1.1 \mathrm{E}-2$ & $2.0 \mathrm{E}-3 \mid$ & $1.1 \mathrm{E}-6$ & $5.1 \mathrm{E}-6$ & $4.4 \mathrm{E}-3$ & $8.4 \mathrm{E}-4$ & $4.0 \mathrm{E}-4$ \\
\hline & \multirow{2}{*}{$(20,10)$} & M. & $4.14 \mathrm{E}-2$ & $2.39 \mathrm{E}-2$ & $1.62 \mathrm{E}-2$ & $4.04 \mathrm{E}-2$ & $7.55 \mathrm{E}-3$ & $3.90 \mathrm{E}-5$ & $1.11 \mathrm{E}-4$ & $6.06 \mathrm{E}-5$ & $4.20 \mathrm{E}-5$ & $2.31 \mathrm{E}-5$ \\
\hline & & Std. & $4.2 \mathrm{E}-3$ & $2.2 \mathrm{E}-3$ & $7.9 \mathrm{E}-3$ & $2.2 \mathrm{E}-3$ & $1.4 \mathrm{E}-3$ & $4.8 \mathrm{E}-7$ & $2.4 \mathrm{E}-6$ & $9.8 \mathrm{E}-6$ & $8.8 \mathrm{E}-7$ & $5.2 \mathrm{E}-5$ \\
\hline \multirow{6}{*}{ FDA2 } & \multirow{2}{*}{$(5,10)$} & M. & $2.85 \mathrm{E}-2$ & $7.28 \mathrm{E}-2$ & $8.13 \mathrm{E}-2$ & $8.40 \mathrm{E}-2$ & $1.50 \mathrm{E}-2$ & $27.00 \mathrm{E}-3$ & $4.18 \mathrm{E}-2$ & $6.93 \mathrm{E}-3$ & $3.55 \mathrm{E}-3$ & $3.25 \mathrm{E}-3$ \\
\hline & & Std. & $2.4 \mathrm{E}-3$ & $3.8 \mathrm{E}-2$ & 3.0E-2 & $1.3 \mathrm{E}-2$ & $1.6 \mathrm{E}-3$ & $1.2 \mathrm{E}-3$ & $1.7 \mathrm{E}-3$ & $1.9 \mathrm{E}-3$ & $1.4 \mathrm{E}-3$ & $7.5 \mathrm{E}-4$ \\
\hline & \multirow{2}{*}{$(10,10)$} & M. & $1.68 \mathrm{E}-3$ & $4.73 \mathrm{E}-2$ & $6.35 \mathrm{E}-2$ & $3.38 \mathrm{E}-2$ & $9.11 \mathrm{E}-3$ & $34.16 \mathrm{E}-3$ & $2.32 \mathrm{E}-2$ & $3.52 \mathrm{E}-3$ & $1.26 \mathrm{E}-3$ & $1.37 \mathrm{E}-3$ \\
\hline & & Std. & $9.0 \mathrm{E}-4$ & 3.3E-2 & $1.0 \mathrm{E}-2$ & $8.8 \mathrm{E}-3$ & $6.3 \mathrm{E}-4$ & 4.7E-4 & $1.4 \mathrm{E}-3$ & $6.2 \mathrm{E}-4$ & 5.4E-4 & $4.8 \mathrm{E}-4$ \\
\hline & \multirow{2}{*}{$(20,10)$} & M. & $6.51 \mathrm{E}-3$ & $3.24 \mathrm{E}-2$ & $6.27 \mathrm{E}-2$ & $1.64 \mathrm{E}-2$ & $6.32 \mathrm{E}-3$ & $31.43 \mathrm{E}-3$ & $6.46 \mathrm{E}-3$ & $1.20 \mathrm{E}-3$ & $3.17 \mathrm{E}-4$ & $4.55 \mathrm{E}-4$ \\
\hline & & Std. & $5.26 \mathrm{E}-4$ & $4.60 \mathrm{E}-2$ & $9.07 \mathrm{E}-3$ & $4.99 \mathrm{E}-3$ & $4.07 \mathrm{E}-4$ & $2.0 \mathrm{E}-5$ & $3.1 \mathrm{E}-4$ & 3.2E-4 & $1.5 \mathrm{E}-4$ & $1.4 \mathrm{E}-4$ \\
\hline \multirow{6}{*}{ FDA3 } & \multirow{2}{*}{$(5,10)$} & M. & $2.63 \mathrm{E}-1$ & $2.63 \mathrm{E}-1$ & $4.43 \mathrm{E}-1$ & $2.47 \mathrm{E}-1$ & $6.25 \mathrm{E}-2$ & $4.23 \mathrm{E}-2$ & $5.19 \mathrm{E}-2$ & $1.28 \mathrm{E}-1$ & $3.08 \mathrm{E}-2$ & $1.05 \mathrm{E}-2$ \\
\hline & & Std. & $6.0 \mathrm{E}-2$ & $3.5 \mathrm{E}-2$ & $1.1 \mathrm{E}-1$ & $2.3 \mathrm{E}-2$ & $3.8 \mathrm{E}-2$ & $1.3 \mathrm{E}-4$ & 3.6E-2 & $5.0 \mathrm{E}-2$ & $9.7 \mathrm{E}-3$ & $5.3 \mathrm{E}-3$ \\
\hline & \multirow{2}{*}{$(10,10)$} & M. & $\begin{array}{l}1.08 \mathrm{E}-1 \\
\end{array}$ & $1.95 \mathrm{E}-1$ & $2.19 \mathrm{E}-1$ & $1.30 \mathrm{E}-1$ & $4.03 \mathrm{E}-2$ & $23.97 \mathrm{E}-2$ & \begin{tabular}{|l|}
$5.68 \mathrm{E}-2$ \\
\end{tabular} & $2.14 \mathrm{E}-1$ & $1.80 \mathrm{E}-2$ & $9.71 \mathrm{E}-3$ \\
\hline & & Std. & 3.3E-2 & 3.2E-2 & $1.8 \mathrm{E}-2$ & $2.5 \mathrm{E}-2$ & $2.9 \mathrm{E}-2$ & 3.6E-5 & $4.4 \mathrm{E}-2$ & 7.2E-2 & $4.5 \mathrm{E}-3$ & $9.4 \mathrm{E}-3$ \\
\hline & \multirow{2}{*}{$(20,10)$} & M. & $9.03 \mathrm{E}-2$ & $1.26 \mathrm{E}-1$ & $1.92 \mathrm{E}-1$ & $5.45 \mathrm{E}-2$ & $3.52 \mathrm{E}-2$ & $23.47 \mathrm{E}-2$ & $4.84 \mathrm{E}-2$ & $4.63 \mathrm{E}-2$ & $1.94 \mathrm{E}-2$ & $1.03 \mathrm{E}-2$ \\
\hline & & Std. & $2.8 \mathrm{E}-3$ & $3.1 \mathrm{E}-2$ & $2.4 \mathrm{E}-2$ & 8.3E-3 & $2.9 \mathrm{E}-2$ & 5.2E-6 & $3.5 \mathrm{E}-2$ & $3.6 \mathrm{E}-2$ & 7.2E-3 & $6.2 \mathrm{E}-3$ \\
\hline \multirow{6}{*}{ FDA4 } & $(5-10)$ & M. & $1.49 \mathrm{E}+0$ & $1.62 \mathrm{E}-1$ & $3.07 \mathrm{E}-1$ & $1.36 \mathrm{E}+0$ & $4.60 \mathrm{E}-1$ & $6.19 \mathrm{E}-4$ & $1.28 \mathrm{E}-2$ & $3.53 \mathrm{E}-4$ & 6.54E-4 & 2.16E-4 \\
\hline & $(5,10)$ & Std. & $1.2 \mathrm{E}-1$ & $6.1 \mathrm{E}-3$ & $1.9 \mathrm{E}-2$ & 1.6E-1 & $6.6 \mathrm{E}-2$ & $1.8 \mathrm{E}-5$ & $1.7 \mathrm{E}-3$ & $1.4 \mathrm{E}-5$ & $2.9 \mathrm{E}-5$ & $1.7 \mathrm{E}-5$ \\
\hline & & M. & $7.63 \mathrm{E}-1$ & $1.24 \mathrm{E}-1$ & $2.11 \mathrm{E}-1$ & $5.77 \mathrm{E}-1$ & $1.83 \mathrm{E}-1$ & $6.20 \mathrm{E}-4$ & $1.25 \mathrm{E}-2$ & $7.35 \mathrm{E}-4$ & $6.58 \mathrm{E}-4$ & $2.16 \mathrm{E}-4$ \\
\hline & $(10,10)$ & Std. & $4.4 \mathrm{E}-2$ & $4.5 \mathrm{E}-3$ & $2.0 \mathrm{E}-2$ & $5.4 \mathrm{E}-2$ & $6.6 \mathrm{E}-3$ & $1.6 \mathrm{E}-5$ & $1.8 \mathrm{E}-3$ & $6.4 \mathrm{E}-5$ & 2.3E-5 & $6.9 \mathrm{E}-6$ \\
\hline & & M. & $2.62 \mathrm{E}-1$ & $1.03 \mathrm{E}-1$ & $1.79 \mathrm{E}-1$ & $2.22 \mathrm{E}-1$ & $1.26 \mathrm{E}-1$ & $3.82 \mathrm{E}-4$ & $8.17 \mathrm{E}-3$ & $2.12 \mathrm{E}-4$ & $3.77 \mathrm{E}-4$ & $7.40 \mathrm{E}-5$ \\
\hline & $(20,10)$ & Std. & $1.6 \mathrm{E}-2$ & $1.7 \mathrm{E}-3$ & 3.0E-3 & $1.3 \mathrm{E}-2$ & $1.5 \mathrm{E}-3$ & $1.4 \mathrm{E}-5$ & $1.2 \mathrm{E}-3$ & $9.8 \mathrm{E}-6$ & $1.4 \mathrm{E}-5$ & $1.8 \mathrm{E}-6$ \\
\hline & $(5-10)$ & M. & $1.76 \mathrm{E}+0$ & $4.33 \mathrm{E}-1$ & $6.55 \mathrm{E}-1$ & $1.57 \mathrm{E}+0$ & $5.23 \mathrm{E}-1$ & $2.50 \mathrm{E}-2$ & $7.21 \mathrm{E}-2$ & $1.81 \mathrm{E}-3$ & $3.93 \mathrm{E}-3$ & $4.73 \mathrm{E}-3$ \\
\hline & $(5,10)$ & Std. & $1.0 \mathrm{E}-1$ & $4.6 \mathrm{E}-2$ & $3.1 \mathrm{E}-2$ & $1.3 \mathrm{E}-1$ & $3.3 \mathrm{E}-2$ & $1.8 \mathrm{E}-4$ & $6.0 \mathrm{E}-3$ & $2.1 \mathrm{E}-4$ & $8.1 \mathrm{E}-4$ & $9.7 \mathrm{E}-4$ \\
\hline FDA5 & & M. & $1.02 \mathrm{E}+0$ & $3.62 \mathrm{E}-1$ & $4.80 \mathrm{E}-1$ & $8.19 \mathrm{E}-1$ & $3.62 \mathrm{E}-1$ & $2.16 \mathrm{E}-2$ & $6.08 \mathrm{E}-2$ & $7.19 \mathrm{E}-3$ & $1.92 \mathrm{E}-3$ & $1.33 \mathrm{e}-03$ \\
\hline & $(10,10)$ & Std. & $5.4 \mathrm{E}-2$ & $4.0 \mathrm{E}-2$ & $3.5 \mathrm{E}-2$ & $6.0 \mathrm{E}-2$ & $8.5 \mathrm{E}-3$ & $2.0 \mathrm{E}-4$ & 3.6E-3 & $5.0 \mathrm{E}-4$ & 2.1E-4 & $1.8 \mathrm{E}-4$ \\
\hline & קט & M. & $4.88 \mathrm{E}-1$ & $3.10 \mathrm{E}-1$ & $3.71 \mathrm{E}-1$ & $4.07 \mathrm{E}-1$ & $3.09 \mathrm{E}-1$ & $1.42 \mathrm{E}-2$ & 3.89E-2 & $3.84 \mathrm{E}-3$ & $1.03 \mathrm{E}-3$ & $5.74 \mathrm{E}-4$ \\
\hline & $(20,10)$ & Std. & $1.2 \mathrm{E}-2$ & $2.7 \mathrm{E}-2$ & $1.2 \mathrm{E}-2$ & 1.4E-2 & $2.2 \mathrm{E}-3$ & $1.3 \mathrm{E}-4$ & $3.5 \mathrm{E}-3$ & $1.6 \mathrm{E}-4$ & $6.2 \mathrm{E}-5$ & $4.6 \mathrm{E}-5$ \\
\hline & $\left(\begin{array}{ll}5 & 10\end{array}\right)$ & M. & $1.31 \mathrm{E}-1$ & $6.95 \mathrm{E}-2$ & $4.15 \mathrm{E}-1$ & $1.36 \mathrm{E}-2$ & $1.12 \mathrm{E}-2$ & $24.06 \mathrm{E}-3$ & $4.39 \mathrm{E}-3$ & $1.48 \mathrm{E}-4$ & $1.10 \mathrm{E}-4$ & $6.58 \mathrm{E}-5$ \\
\hline & $(5,10)$ & Std. & $1.1 \mathrm{E}-2$ & 1.4E-2 & 7.4E-1 & $9.0 \mathrm{E}-3$ & 8.1E-3 & $2.8 \mathrm{E}-7$ & $1.8 \mathrm{E}-3$ & $1.8 \mathrm{E}-5$ & $8.3 \mathrm{E}-6$ & $3.5 \mathrm{E}-6$ \\
\hline dMOP1 & & M. & $8.83 \mathrm{E}-3$ & $3.93 \mathrm{E}-2$ & $5.09 \mathrm{E}-2$ & $9.39 \mathrm{E}-3$ & $8.24 \mathrm{E}-3$ & $32.02 \mathrm{E}-3$ & $2.29 \mathrm{E}-3$ & $1.28 \mathrm{E}-3$ & $9.96 \mathrm{E}-5$ & $5.30 \mathrm{E}-5$ \\
\hline & (10, & Std. & $5.0 \mathrm{E}-3$ & $6.2 \mathrm{E}-3$ & $9.3 \mathrm{E}-2$ & $4.3 \mathrm{E}-3$ & $5.3 \mathrm{E}-3$ & $2.2 \mathrm{E}-7$ & $1.4 \mathrm{E}-3$ & $2.8 \mathrm{E}-5$ & $1.2 \mathrm{E}-5$ & $4.7 \mathrm{E}-6$ \\
\hline & & M. & $7.39 \mathrm{E}-3$ & $1.88 \mathrm{E}-2$ & $4.39 \mathrm{E}-2$ & $7.17 \mathrm{E}-3$ & $6.54 \mathrm{E}-3$ & $32.71 \mathrm{E}-3$ & $2.71 \mathrm{E}-3$ & $2.03 \mathrm{E}-3$ & $5.02 \mathrm{E}-5$ & $1.98 \mathrm{E}-5$ \\
\hline & $(0,10)$ & Std. & $3.2 \mathrm{E}-3$ & $2.3 \mathrm{E}-3$ & $8.4 \mathrm{E}-2$ & $2.7 \mathrm{E}-3$ & $3.0 \mathrm{E}-3$ & $1.3 \mathrm{E}-7$ & $1.0 \mathrm{E}-7$ & $6.3 \mathrm{E}-6$ & $9.1 \mathrm{E}-7$ & 7.4E-7 \\
\hline & & M. & $6.87 \mathrm{E}-1$ & $1.20 \mathrm{E}-1$ & $1.56 \mathrm{E}-1$ & $4.91 \mathrm{E}-1$ & $3.02 \mathrm{E}-2$ & $21.59 \mathrm{E}-3$ & $4.19 \mathrm{E}-3$ & $6.98 \mathrm{E}-4$ & $1.87 \mathrm{E}-3$ & $1.70 \mathrm{E}-3$ \\
\hline & $(5,10)$ & Std. & $7.5 \mathrm{E}-2$ & $2.0 \mathrm{E}-2$ & $1.8 \mathrm{E}-2$ & $4.1 \mathrm{E}-2$ & 3.4E-3 & $6.0 \mathrm{E}-7$ & $6.6 \mathrm{E}-3$ & $2.6 \mathrm{E}-4$ & $1.5 \mathrm{E}-3$ & $4.3 \mathrm{E}-4$ \\
\hline dMOP2 & & M. & $1.18 \mathrm{E}-1$ & $7.32 \mathrm{E}-2$ & $4.28 \mathrm{E}-1$ & $1.88 \mathrm{E}-1$ & $1.21 \mathrm{E}-2$ & $26.33 \mathrm{E}-4$ & $2.95 \mathrm{E}-3$ & $1.08 \mathrm{E}-3$ & $6.10 \mathrm{E}-4$ & $6.06 \mathrm{E}-4$ \\
\hline & & Std. & $9.4 \mathrm{E}-3$ & $8.9 \mathrm{E}-3$ & $1.7 \mathrm{E}-2$ & $1.9 \mathrm{E}-2$ & $5.7 \mathrm{E}-4$ & $2.0 \mathrm{E}-6$ & 8.7E-3 & $3.0 \mathrm{E}-4$ & $6.4 \mathrm{E}-5$ & $8.3 \mathrm{E}-5$ \\
\hline & & M. & $1.57 \mathrm{E}-1$ & $3.46 \mathrm{E}-2$ & $2.02 \mathrm{E}-2$ & $5.63 \mathrm{E}-2$ & $6.32 \mathrm{E}-3$ & $31.92 \mathrm{E}-3$ & $2.70 \mathrm{E}-3$ & $1.88 \mathrm{E}-3$ & $1.42 \mathrm{E}-3$ & $1.61 \mathrm{E}-3$ \\
\hline & , 10) & Std. & $6.70 \mathrm{E}-4$ & 4.32E-3 & $2.49 \mathrm{E}-3$ & $3.91 \mathrm{E}-3$ & $1.74 \mathrm{E}-4$ & 3.7E-7 & 4.2E-3 & $5.8 \mathrm{E}-5$ & 5.2E-4 & $5.8 \mathrm{E}-4$ \\
\hline & & M. & $5.62 \mathrm{E}-1$ & $4.95 \mathrm{E}-2$ & $1.76 \mathrm{E}-1$ & $3.42 \mathrm{E}-1$ & $1.81 \mathrm{E}-1$ & $9.13 \mathrm{E}-1$ & $1.19 \mathrm{E}+0$ & $5.40 \mathrm{E}-1$ & \begin{tabular}{|l|}
$5.02 \mathrm{E}-1$ \\
\end{tabular} & \begin{tabular}{|c|}
$6.67 \mathrm{E}-1$ \\
\end{tabular} \\
\hline & $(5,10)$ & Std. & $3.9 \mathrm{E}-2$ & $4.8 \mathrm{E}-3$ & $8.0 \mathrm{E}-2$ & $1.9 \mathrm{E}-2$ & $9.6 \mathrm{E}-2$ & $2.9 \mathrm{E}-1$ & $5.2 \mathrm{E}-2$ & $4.0 \mathrm{E}-2$ & $1.1 \mathrm{E}-2$ & $9.7 \mathrm{E}-2$ \\
\hline dMOP3 & & M. & $2.00 \mathrm{E}-1$ & $2.95 \mathrm{E}-2$ & $1.13 \mathrm{E}-1$ & $1.68 \mathrm{E}-1$ & $1.32 \mathrm{E}-1$ & $2.67 \mathrm{E}-1$ & $2.95 \mathrm{E}-1$ & $2.51 \mathrm{E}-1$ & $1.03 \mathrm{E}-1$ & $1.93 \mathrm{E}-1$ \\
\hline & & Std. & $1.5 \mathrm{E}-2$ & 2.4E-3 & $1.2 \mathrm{E}-2$ & $1.0 \mathrm{E}-2$ & $1.3 \mathrm{E}-2$ & $2.0 \mathrm{E}-2$ & 4.2E-3 & $1.4 \mathrm{E}-2$ & 2.7E-2 & $2.8 \mathrm{E}-2$ \\
\hline & & M. & $1.07 \mathrm{E}-1$ & $1.63 \mathrm{E}-2$ & $8.99 \mathrm{E}-2$ & $6.27 \mathrm{E}-2$ & $8.15 \mathrm{E}-2$ & $25.04 \mathrm{E}+0$ & $8.88 \mathrm{E}+0$ & $7.44 \mathrm{E}+0$ & $3.27 \mathrm{E}+0$ & $5.11 \mathrm{E}+0$ \\
\hline & & Std. & $8.50 \mathrm{E}-3$ & $1.71 \mathrm{E}-3$ & & & $1.25 \mathrm{E}-2$ & & & $1.7 \mathrm{E}+0$ & $6.8 \mathrm{E}-1$ & \\
\hline
\end{tabular}

TABLE XIII: Adjusted p-values over IGD for FDA and dMOP problems with $\tau_{t}=5$ and $n_{t}=10$ while DPb-MOPSO is the control method, $\alpha=0.05$.

\begin{tabular}{|l|c|c|c|c|c|c|}
\hline $\mathrm{i}$ & DPb-MOPSO vs. & unadjusted $p$ & $p_{\text {Bonf }}$ & $p_{\text {Holm }}$ & $p_{\text {Hochberg }}$ & $p_{L i}$ \\
\hline 1 & DNSGAII & 0.000044 & 0.000393 & 0.000393 & 0.000393 & 0.000169 \\
2 & MOEAD & 0.000384 & 0.003459 & 0.003075 & 0.003075 & 0.001483 \\
3 & PPS & 0.000711 & 0.006395 & 0.004974 & 0.004974 & 0.002738 \\
4 & dCOEA & 0.011787 & 0.106084 & 0.070723 & 0.070723 & 0.043558 \\
5 & SGEA & 0.038989 & 0.350898 & 0.194943 & 0.194943 & 0.130919 \\
6 & dMOPSO & 0.06928 & 0.623519 & 0.27712 & 0.27712 & 0.211156 \\
7 & MOPSO & 0.457391 & 4.116515 & 1.372172 & 0.741182 & 0.638627 \\
8 & pbMOPSO & 0.620294 & 5.582646 & 1.372172 & 0.741182 & 0.705591 \\
9 & Dynamic-MOPSO & 0.741182 & 6.670634 & 1.372172 & 0.741182 & 0.741182 \\
\hline
\end{tabular}

problems with moderate changes. We can see the significant improvement of DPb-MOPSO compared to dCOEA, MOEAD, DNSGA-II, PPS, dMOPSO, SGEA, MOPSO, pbMOPSO and Dynamic-MOPSO for all post-hoc procedures. Except for the Bonferroni-Dunn procedure, the DPb-MOPSO has the same significance level compared to Dynamic-MOPSO with a APV $>0.05$. Also, it has the best significance as the MOEAD, dCOEA, DNSGA-II, PPS and SGEA while it is the same for the pbMOPSO, Dynamic-MOPSO, MOPSO and dMOPSO
TABLE XIV: Adjusted p-values over HVD metric for FDA and dMOP problems with $\tau_{t}=5$ and $n_{t}=10$ while DPbMOPSO is the control method, $\alpha=0.05$.

\begin{tabular}{|c|c|c|c|c|c|c|}
\hline $\mathrm{i}$ & DPb-MOPSO vs. & unadjusted $p$ & $p_{\text {Bonf }}$ & $p_{\text {Holm }}$ & $p_{\text {Hochberg }}$ & $p_{L i}$ \\
\hline 1 & MOEAD & 0.000018 & 0.000158 & 0.000158 & 0.000158 & 0.000267 \\
2 & DNSGAII & 0.000074 & 0.000665 & 0.000591 & 0.000517 & 0.001121 \\
3 & PPS & 0.000074 & 0.000665 & 0.000591 & 0.000517 & 0.001121 \\
4 & dCOEA & 0.002249 & 0.020244 & 0.013496 & 0.013496 & 0.03305 \\
5 & SGEA & 0.013243 & 0.119186 & 0.066215 & 0.066215 & 0.167523 \\
6 & Dynamic-MOPSO & 0.56326 & 5.069341 & 2.25304 & 0.934192 & 0.895388 \\
7 & pbMOPSO & 0.620294 & 5.582646 & 2.25304 & 0.934192 & 0.904084 \\
8 & MOPSO & 0.934192 & 8.407725 & 2.25304 & 0.934192 & 0.934192 \\
9 & dMOPSO & 0.934192 & 8.407725 & 2.25304 & 0.934192 & 0.934192 \\
\hline
\end{tabular}

over HVD metric such as reported on Table XI.

For severe environmental changes, Table XIII presents the significant difference between the DPb-MOPSO and DNSGAII, MOEAD and PPS for all pot-hoc procedures and dCOEA using the $\mathrm{Li}$ procedure with a $p$-value $\leq 0.05$ for the IGD metric. In addition, we can infer that there is no difference with $p$-value $>0.05$ likewise SGEA, dMOPSO, MOPSO, pbMOPSO, Dynamic-MOPSO and dCOEA using Bonferroni-Dunn, Holm and Hochberg procedures. All APV 
TABLE XV: Mean and Standard Deviation Values of all MOEAs over HVD Metric for FDA and dMOP.

\begin{tabular}{|c|c|c|c|c|c|c|c|c|c|c|c|}
\hline \multirow{2}{*}{ Prob. } & \multirow{2}{*}{$\left(\tau_{t}, n_{t}\right)$} & \multicolumn{5}{|c|}{ Tested Algorithms of Jiang et al. [13] } & \multicolumn{5}{|c|}{ MOPSO-based Algorithms } \\
\hline & & Val. DNSGA-II & $\mathrm{I}$ dCOEA & PPS & MOEA/D & SGEA & MOPSO & dMOPSO & pbMOPSC & Dynamic-MOPSO & DPb-MOPSO \\
\hline \multirow{6}{*}{ FDA1 } & \multirow{2}{*}{$(5,10)$} & \begin{tabular}{l|l} 
M. & $8.70 \mathrm{E}-1$ \\
\end{tabular} & $1.25 \mathrm{E}-1$ & $3.87 \mathrm{E}-1$ & $7.70 \mathrm{E}-1$ & $8.14 \mathrm{E}-2$ & $3.83 \mathrm{E}-3$ & $4.48 \mathrm{E}-3$ & $-1.82 \mathrm{E}-1$ & $-1.52 \mathrm{E}-1$ & $-1.69 \mathrm{E}-1$ \\
\hline & & Std. $7.5 \mathrm{E}-2$ & $2.4 \mathrm{E}-2$ & $1.0 \mathrm{E}-1$ & $9.4 \mathrm{E}-2$ & $2.0 \mathrm{E}-2$ & $1.6 \mathrm{E}-4$ & $6.3 \mathrm{E}-5$ & $2.5 \mathrm{E}-1$ & $1.7 \mathrm{E}-1$ & $4.6 \mathrm{E}-2$ \\
\hline & \multirow{2}{*}{$(10,10)$} & M. $1.36 \mathrm{E}-1$ & $8.52 \mathrm{E}-2$ & $2.97 \mathrm{E}-1$ & $2.88 \mathrm{E}-1$ & $3.81 \mathrm{E}-2$ & $4.14 \mathrm{E}-3$ & $4.56 \mathrm{E}-3$ & $-1.52 \mathrm{E}-3$ & $-4.77 \mathrm{E}-2$ & $-9.20 \mathrm{E}-3$ \\
\hline & & Std. $1.7 \mathrm{E}-2$ & $2.0 \mathrm{E}-2$ & $1.6 \mathrm{E}-2$ & $2.9 \mathrm{E}-2$ & $1.4 \mathrm{E}-2$ & $6.4 \mathrm{E}-5$ & $4.0 \mathrm{E}-5$ & $4.4 \mathrm{E}-2$ & 8.1E-2 & $6.3 \mathrm{E}-2$ \\
\hline & \multirow{2}{*}{$(20,10)$} & M. $3.55 \mathrm{E}-2$ & $5.46 \mathrm{E}-2$ & $2.84 \mathrm{E}-1$ & $1.34 \mathrm{E}-1$ & $2.02 \mathrm{E}-2$ & $4.30 \mathrm{E}-3$ & $4.65 \mathrm{E}-3$ & $2.32 \mathrm{E}-3$ & $3.41 \mathrm{E}-3$ & $-1.62 \mathrm{E}-3$ \\
\hline & & Std. $1.3 \mathrm{E}-2$ & $1.6 \mathrm{E}-2$ & $1.5 \mathrm{E}-2$ & $9.2 \mathrm{E}-3$ & $1.2 \mathrm{E}-2$ & $3.6 \mathrm{E}-5$ & $1.7 E-5$ & $6.9 \mathrm{E}-4$ & $1.4 \mathrm{E}-4$ & $7.8 \mathrm{E}-3$ \\
\hline \multirow{6}{*}{ FDA2 } & \multirow{2}{*}{$(5,10)$} & \begin{tabular}{l|l|} 
M. & $4.71 \mathrm{E}-2$ \\
\end{tabular} & $1.85 \mathrm{E}-1$ & $3.21 \mathrm{E}-1$ & $1.30 \mathrm{E}-1$ & $2.54 \mathrm{E}-2$ & $-8.99 \mathrm{E}+0$ & $-9.96 E+0$ & $-1.30 \mathrm{E}+0$ & $-3.94 \mathrm{E}+0$ & $-3.74 \mathrm{E}+0$ \\
\hline & & Std. $1.4 \mathrm{E}-2$ & $6.4 \mathrm{E}-2$ & $6.7 \mathrm{E}-2$ & $2.5 \mathrm{E}-2$ & $1.3 \mathrm{E}-2$ & 8.5E-1 & $1.4 \mathrm{E}+0$ & $6.4 \mathrm{E}-1$ & $1.1 \mathrm{E}+1$ & $1.4 \mathrm{E}+0$ \\
\hline & \multirow{2}{*}{$(10,10)$} & M. $2.05 \mathrm{E}-2$ & $1.24 \mathrm{E}-1$ & $2.66 \mathrm{E}-1$ & $6.29 \mathrm{E}-2$ & $1.67 \mathrm{E}-2$ & $8.54 \mathrm{E}+0$ & $-9.72 E+0$ & $-6.21 \mathrm{E}+0$ & $-1.36 \mathrm{E}+0$ & $-1.08 \mathrm{E}+0$ \\
\hline & & Std. $1.4 \mathrm{E}-2$ & $4.6 \mathrm{E}-2$ & $1.4 \mathrm{E}-2$ & $1.8 \mathrm{E}-2$ & $1.4 \mathrm{E}-2$ & $3.2 \mathrm{E}-1$ & $1.4 \mathrm{E}+0$ & $1.4 \mathrm{E}+1$ & $6.5 \mathrm{E}-1$ & $8.9 \mathrm{E}-1$ \\
\hline & \multirow{2}{*}{$(20,10)$} & M. $1.33 \mathrm{E}-2$ & $8.64 \mathrm{E}-2$ & $2.55 \mathrm{E}-1$ & $3.24 \mathrm{E}-2$ & $1.23 \mathrm{E}-2$ & $-8.43 \mathrm{E}+0$ & $-8.19 \mathrm{E}+0$ & $-3.68 \mathrm{E}+0$ & $-3.78 \mathrm{E}-1$ & $-2.51 \mathrm{E}+0$ \\
\hline & & Std. $1.4 \mathrm{E}-2$ & $7.0 \mathrm{E}-2$ & $9.4 \mathrm{E}-3$ & $1.4 \mathrm{E}-2$ & $1.4 \mathrm{E}-2$ & $1.8 \mathrm{E}-2$ & $1.1 \mathrm{E}+0$ & $7.8 \mathrm{E}+0$ & $4.3 \mathrm{E}-1$ & $1.4 \mathrm{E}+0$ \\
\hline \multirow{6}{*}{ FDA3 } & \multirow{2}{*}{$(5,10)$} & \begin{tabular}{|l|l|} 
M. & $1.54 \mathrm{E}+0$ \\
\end{tabular} & $1.45 \mathrm{E}+0$ & $1.75 \mathrm{E}+0$ & $1.66 \mathrm{E}+0$ & $9.80 \mathrm{E}-1$ & $-4.86 \mathrm{E}-1$ & $-4.27 \mathrm{E}-1$ & -5.36E-1 & $-2.60 \mathrm{E}-1$ & $-1.12 \mathrm{E}-1$ \\
\hline & & Std. $1.6 \mathrm{E}-1$ & $8.5 \mathrm{E}-2$ & $1.8 \mathrm{E}-1$ & $7.8 \mathrm{E}-2$ & $1.0 \mathrm{E}-1$ & 8.2E-3 & 2.6E-1 & $4.9 \mathrm{E}-1$ & $1.2 \mathrm{E}-1$ & $6.2 \mathrm{E}-2$ \\
\hline & \multirow{2}{*}{$(10,10)$} & \begin{tabular}{|l|l} 
M. & $1.09 \mathrm{E}+0$
\end{tabular} & $1.32 \mathrm{E}+0$ & $1.16 \mathrm{E}+0$ & $1.12 \mathrm{E}+0$ & $9.24 \mathrm{E}-1$ & $-5.62 \mathrm{E}-1$ & $-5.27 \mathrm{E}-1$ & $-6.57 \mathrm{E}-1$ & $-2.68 \mathrm{E}-1$ & $6.10 \mathrm{E}-1$ \\
\hline & & Std. 9.9E-2 & 7.7E-2 & $4.6 \mathrm{E}-2$ & $9.3 \mathrm{E}-2$ & $8.2 \mathrm{E}-2$ & $6.5 \mathrm{E}-4$ & $1.9 \mathrm{E}-1$ & $4.6 \mathrm{E}-1$ & $1.0 \mathrm{E}-1$ & 3.7E-1 \\
\hline & \multirow{2}{*}{$(20,10)$} & \begin{tabular}{l|l} 
M. & $1.04 \mathrm{E}+0$
\end{tabular} & $1.15 \mathrm{E}+0$ & $1.03 \mathrm{E}+0$ & $9.47 \mathrm{E}-1$ & $9.11 \mathrm{E}-1$ & $-5.54 \mathrm{E}-1$ & $-4.13 \mathrm{E}-1$ & $-2.95 \mathrm{E}-1$ & $-3.09 \mathrm{E}-1$ & $-1.66 \mathrm{E}-1$ \\
\hline & & Std. 7.9E-2 & $6.6 \mathrm{E}-2$ & 7.4E-2 & $2.2 \mathrm{E}-2$ & $8.1 \mathrm{E}-2$ & 2.1E-4 & $3.6 \mathrm{E}-1$ & $2.9 \mathrm{E}-1$ & $1.4 \mathrm{E}-1$ & $1.1 \mathrm{E}-1$ \\
\hline \multirow{6}{*}{ FDA4 } & & \begin{tabular}{|l|l|} 
M. & $2.05 \mathrm{E}+0$ \\
\end{tabular} & $3.80 \mathrm{E}-1$ & $7.77 \mathrm{E}-1$ & $3.97 \mathrm{E}+0$ & $1.03 \mathrm{E}+0$ & $4.17 \mathrm{E}-2$ & $-6.51 \mathrm{E}+1$ & $6.18 \mathrm{E}-3$ & $2.89 \mathrm{E}-2$ & $1.24 \mathrm{E}-4$ \\
\hline & $(5,10)$ & Std. 2.0E-1 & $2.6 \mathrm{E}-2$ & $6.8 \mathrm{E}-2$ & $1.6 \mathrm{E}+0$ & $1.3 \mathrm{E}-1$ & $4.6 \mathrm{E}-3$ & 7.3E+0 & 3.3E-3 & $6.7 \mathrm{E}-3$ & $1.9 \mathrm{E}-3$ \\
\hline & & \begin{tabular}{l|l|} 
M. & $1.58 \mathrm{E}+0$
\end{tabular} & $2.70 \mathrm{E}-1$ & $4.34 \mathrm{E}-1$ & $1.24 \mathrm{E}+0$ & $2.74 \mathrm{E}-1$ & $4.26 \mathrm{E}-2$ & $-6.92 \mathrm{E}+1$ & $5.67 \mathrm{E}-3$ & $3.16 \mathrm{E}-2$ & $7.82 \mathrm{E}-3$ \\
\hline & $(10,10)$ & Std. 6.6E-2 & $3.5 \mathrm{E}-2$ & 7.2E-2 & $1.3 \mathrm{E}-1$ & $2.4 \mathrm{E}-2$ & $5.0 \mathrm{E}-3$ & $8.2 \mathrm{E}+0$ & $2.5 \mathrm{E}-3$ & $5.6 \mathrm{E}-3$ & $1.3 \mathrm{E}-3$ \\
\hline & & M. $5.48 \mathrm{E}-1$ & $1.80 \mathrm{E}-1$ & $3.34 \mathrm{E}-1$ & $4.34 \mathrm{E}-1$ & $1.44 \mathrm{E}-1$ & $4.41 \mathrm{E}-2$ & $-7.01 \mathrm{E}+1$ & $5.66 \mathrm{E}-3$ & $5.00 \mathrm{E}-2$ & $5.19 \mathrm{E}-4$ \\
\hline & $(20,10)$ & Std. $5.7 \mathrm{E}-2$ & $2.4 \mathrm{E}-2$ & $8.3 \mathrm{E}-3$ & $5.0 \mathrm{E}-2$ & $2.0 \mathrm{E}-2$ & $4.0 \mathrm{E}-3$ & $8.5 \mathrm{E}+0$ & $2.2 \mathrm{E}-3$ & $3.8 \mathrm{E}-3$ & $6.3 \mathrm{E}-4$ \\
\hline & & \begin{tabular}{|l|l|} 
M. & $6.75 \mathrm{E}+0$ \\
\end{tabular} & $2.76 \mathrm{E}+0$ & $3.88 \mathrm{E}+0$ & $7.08 \mathrm{E}+0$ & $2.70 \mathrm{E}+0$ & $-6.38 \mathrm{E}-1$ & -9.97E-1 & $4.97 \mathrm{E}-2$ & $-3.52 \mathrm{E}-2$ & $-2.99 \mathrm{E}-1$ \\
\hline & & Std. $1.9 \mathrm{E}-1$ & $2.8 \mathrm{E}-1$ & $3.1 \mathrm{E}-1$ & $1.0 \mathrm{E}+0$ & $2.2 \mathrm{E}-1$ & $6.1 \mathrm{E}-1$ & $5.5 \mathrm{E}+0$ & $1.5 \mathrm{E}-2$ & $9.2 \mathrm{E}-2$ & $1.2 \mathrm{E}-1$ \\
\hline FDA5 & & \begin{tabular}{|l|l|} 
M. & $5.41 \mathrm{E}+0$
\end{tabular} & $2.37 \mathrm{E}+0$ & $2.19 \mathrm{E}+0$ & $4.80 \mathrm{E}+0$ & $1.88 \mathrm{E}+0$ & $-8.66 \mathrm{E}-1$ & $-5.97 \mathrm{E}-1$ & $5.85 \mathrm{E}-2$ & $4.59 \mathrm{E}-2$ & $3.97 \mathrm{E}-2$ \\
\hline & $(10,10)$ & Std. $1.6 \mathrm{E}-1$ & $2.7 \mathrm{E}-1$ & $3.9 \mathrm{E}-1$ & $2.6 \mathrm{E}-1$ & $9.3 \mathrm{E}-2$ & $6.7 \mathrm{E}-1$ & $3.8 \mathrm{E}+0$ & $6.8 \mathrm{E}-2$ & $1.6 \mathrm{E}-2$ & $2.4 \mathrm{E}-2$ \\
\hline & & \begin{tabular}{|l|l|} 
M. & $2.64 \mathrm{E}+0$ \\
\end{tabular} & $2.02 \mathrm{E}+0$ & $1.04 \mathrm{E}+0$ & $2.15 \mathrm{E}+0$ & $1.78 \mathrm{E}+0$ & $-1.51 \mathrm{E}+0$ & $-1.47 \mathrm{E}+0$ & $-4.18 \mathrm{E}-1$ & $4.83 \mathrm{E}-2$ & $1.25 \mathrm{E}-3$ \\
\hline & $(20,10)$ & Std. $1.1 \mathrm{E}-1$ & $1.8 \mathrm{E}-1$ & $1.1 \mathrm{E}-1$ & $1.0 \mathrm{E}-1$ & $7.1 \mathrm{E}-2$ & $5.4 \mathrm{E}-1$ & $5.4 \mathrm{E}+0$ & $3.9 \mathrm{E}-2$ & $8.8 \mathrm{E}-3$ & $4.4 \mathrm{E}-3$ \\
\hline & $(5-10)$ & \begin{tabular}{l|l} 
M. & $3.93 \mathrm{E}-2$ \\
\end{tabular} & $1.73 \mathrm{E}-1$ & $2.86 \mathrm{E}-1$ & $4.64 \mathrm{E}-2$ & $3.75 \mathrm{E}-2$ & -3.29E-1 & $-3.07 \mathrm{E}-1$ & $-9.10 \mathrm{E}-4$ & $9.92 \mathrm{E}-4$ & $-9.74 \mathrm{E}-4$ \\
\hline & $(5,10)$ & Std. $3.81 \mathrm{E}-2$ & $3.3 \mathrm{E}-2$ & $3.6 \mathrm{E}-1$ & 3.6E-2 & $2.5 \mathrm{E}-2$ & 9.9E-5 & $1.2 \mathrm{E}-1$ & $1.2 \mathrm{E}-3$ & $9.6 \mathrm{E}-4$ & $4.0 \mathrm{E}-4$ \\
\hline dMOP1 & & \begin{tabular}{l|l} 
M. $2.28 \mathrm{E}-2$ \\
\end{tabular} & $1.12 \mathrm{E}-1$ & $9.27 \mathrm{E}-2$ & $2.57 \mathrm{E}-2$ & $1.90 \mathrm{E}-2$ & $-3.29 \mathrm{E}-1$ & $-3.29 \mathrm{E}-1$ & $-1.33 \mathrm{E}-4$ & $2.13 \mathrm{E}-3$ & $1.46 \mathrm{E}-4$ \\
\hline & $(10,10)$ & Std. $2.0 \mathrm{E}-2$ & $2.0 \mathrm{E}-2$ & $1.3 \mathrm{E}-1$ & $1.5 \mathrm{E}-2$ & $1.4 \mathrm{E}-2$ & $5.9 \mathrm{E}-5$ & $3.3 \mathrm{E}-5$ & $8.4 \mathrm{E}-4$ & $3.2 \mathrm{E}-4$ & $4.4 \mathrm{E}-4$ \\
\hline & & \begin{tabular}{l|l} 
M. & $1.71 \mathrm{E}-2$
\end{tabular} & $5.65 \mathrm{E}-2$ & $6.02 \mathrm{E}-2$ & $1.59 \mathrm{E}-2$ & $1.80 \mathrm{E}-2$ & $-3.29 \mathrm{E}-1$ & $-3.29 \mathrm{E}-1$ & $-2.45 \mathrm{E}-1$ & $2.79 \mathrm{E}-3$ & $1.12 \mathrm{E}-4$ \\
\hline & $(20,10)$ & Std. $1.4 \mathrm{E}-2$ & $8.1 \mathrm{E}-3$ & $8.1 \mathrm{E}-2$ & 7.9E-3 & $1.3 \mathrm{E}-2$ & $3.6 \mathrm{E}-5$ & $1.7 \mathrm{E}-5$ & $2.6 \mathrm{E}-3$ & $2.7 \mathrm{E}-4$ & $1.4 \mathrm{E}-4$ \\
\hline & & \begin{tabular}{l|l} 
M. & $8.06 \mathrm{E}-1$
\end{tabular} & $3.03 \mathrm{E}-1$ & $3.95 \mathrm{E}-1$ & $9.04 \mathrm{E}-1$ & $8.71 \mathrm{E}-2$ & $-1.08 \mathrm{E}-1$ & $-1.98 \mathrm{E}-2$ & $9.71 \mathrm{E}-3$ & $-1.05 \mathrm{E}-1$ & $-1.16 \mathrm{E}-1$ \\
\hline & & Std. $1.1 \mathrm{E}-1$ & $4.9 \mathrm{E}-2$ & $3.9 \mathrm{E}-2$ & $7.3 \mathrm{E}-2$ & $1.9 \mathrm{E}-2$ & $8.2 \mathrm{E}-5$ & $2.2 \mathrm{E}-1$ & $2.6 \mathrm{E}-2$ & $5.6 \mathrm{E}-2$ & 1.3E-2 \\
\hline dMOP2 & & \begin{tabular}{l|l|} 
M. & $2.90 \mathrm{E}-1$
\end{tabular} & $2.07 \mathrm{E}-1$ & $1.17 \mathrm{E}-1$ & $4.46 \mathrm{E}-1$ & $3.59 \mathrm{E}-2$ & -1.08E-1 & $-8.61 \mathrm{E}-2$ & $-3.94 \mathrm{E}-3$ & $-8.63 \mathrm{E}-2$ & $-6.00 \mathrm{E}-2$ \\
\hline & & Std. $2.5 \mathrm{E}-2$ & 2.4E-2 & $4.3 \mathrm{E}-2$ & $4.2 \mathrm{E}-2$ & $1.1 \mathrm{E}-2$ & 6.1E-5 & $1.2 \mathrm{E}-1$ & 3.3E-2 & $3.7 \mathrm{E}-2$ & $4.4 \mathrm{E}-2$ \\
\hline & & \begin{tabular}{l|l} 
M. & $4.50 \mathrm{E}-2$
\end{tabular} & $1.09 \mathrm{E}-1$ & $5.65 \mathrm{E}-2$ & $1.98 \mathrm{E}-1$ & $1.85 \mathrm{E}-2$ & -1.08E-1 & $-8.57 \mathrm{E}-2$ & $-1.06 \mathrm{E}-1$ & $-6.42 \mathrm{E}-2$ & $-9.12 \mathrm{E}-2$ \\
\hline & $(20,10)$ & Std. $1.2 \mathrm{E}-2$ & $1.5 \mathrm{E}-2$ & $6.2 \mathrm{E}-3$ & $1.4 \mathrm{E}-2$ & $1.1 \mathrm{E}-2$ & 3.3E-5 & $1.2 \mathrm{E}-1$ & $2.4 \mathrm{E}-3$ & $4.4 \mathrm{E}-2$ & $3.9 \mathrm{E}-2$ \\
\hline & & \begin{tabular}{|l|l} 
M. & $9.51 \mathrm{E}-1$ \\
\end{tabular} & $1.05 \mathrm{E}-1$ & $4.22 \mathrm{E}-1$ & $7.61 \mathrm{E}-1$ & $4.07 \mathrm{E}-1$ & $-1.13 \mathrm{E}+1$ & $-1.10 \mathrm{E}+1$ & $-1.40 \mathrm{E}+1$ & $-1.44 \mathrm{E}+1$ & $-1.45 \mathrm{E}+1$ \\
\hline & $(5,10)$ & Std. $3.4 \mathrm{E}-2$ & $1.6 \mathrm{E}-2$ & $1.5 \mathrm{E}-2$ & $5.3 \mathrm{E}-2$ & $2.4 \mathrm{E}-2$ & $1.2 \mathrm{E}+0$ & $1.3 \mathrm{E}-1$ & $6.4 \mathrm{E}-1$ & $2.2 \mathrm{E}-1$ & 4.5E-1 \\
\hline dMOP3 & & M. $4.74 \mathrm{E}-1$ & $6.57 \mathrm{E}-2$ & $2.79 \mathrm{E}-1$ & $4.54 \mathrm{E}-1$ & $3.18 \mathrm{E}-1$ & $2.49 \mathrm{E}+0$ & $2.63 \mathrm{E}+0$ & $1.20 \mathrm{E}+0$ & $-8.80 \mathrm{E}-1$ & $-6.10 \mathrm{E}-2$ \\
\hline & & Std. $2.8 \mathrm{E}-2$ & $1.3 \mathrm{E}-2$ & $2.7 \mathrm{E}-2$ & $2.8 \mathrm{E}-2$ & $2.9 \mathrm{E}-2$ & $1.1 \mathrm{E}+0$ & $2.8 \mathrm{E}-1$ & $3.5 \mathrm{E}+0$ & 2.2E-1 & $1.1 \mathrm{E}+0$ \\
\hline & & \begin{tabular}{|l|l|} 
M. & $2.76 \mathrm{E}-1$
\end{tabular} & $3.63 \mathrm{E}-2$ & $2.21 \mathrm{E}-1$ & $2.87 \mathrm{E}-1$ & $2.15 \mathrm{E}-1$ & $-1.63 E+1$ & $-1.73 \mathrm{E}+1$ & $-1.65 \mathrm{E}+1$ & $-1.93 \mathrm{E}+1$ & $-1.99 \mathrm{E}+1$ \\
\hline & $(2$ & Std. $2.5 \mathrm{E}-2$ & $1.3 \mathrm{E}-2$ & $1.5 \mathrm{E}-2$ & 2.0E-2 & $3.0 \mathrm{E}-2$ & $1.9 \mathrm{E}+0$ & $1.3 \mathrm{E}-1$ & $1.6 \mathrm{E}+0$ & $4.6 \mathrm{E}+0$ & $3.5 \mathrm{E}+0$ \\
\hline
\end{tabular}

TABLE XVI: Adjusted p-values over IGD for FDA and dMOP problems with $\tau_{t}=20$ and $n_{t}=10$ while DPb-MOPSO is the control method, $\alpha=0.05$.

\begin{tabular}{|c|c|c|c|c|c|c|}
\hline $\mathrm{i}$ & DPb-MOPSO vs. & unadjusted $p$ & $p_{\text {Bonf }}$ & $p_{\text {Holm }}$ & $p_{\text {Hochberg }}$ & $p_{L i}$ \\
\hline 1 & DNSGAII & 0.000025 & 0.000229 & 0.000229 & 0.000229 & 0.00013 \\
2 & PPS & 0.000104 & 0.000937 & 0.000833 & 0.000833 & 0.000532 \\
3 & MOEAD & 0.000384 & 0.003459 & 0.00269 & 0.00269 & 0.001961 \\
4 & dCOEA & 0.000957 & 0.008612 & 0.005742 & 0.005742 & 0.004867 \\
5 & dMOPSO & 0.014856 & 0.1337 & 0.074278 & 0.074278 & 0.070572 \\
6 & SGEA & 0.031803 & 0.286226 & 0.127212 & 0.127212 & 0.139824 \\
7 & MOPSO & 0.200591 & 1.805317 & 0.601772 & 0.430999 & 0.506239 \\
8 & pbMOPSO & 0.2155 & 1.939496 & 0.601772 & 0.430999 & 0.524143 \\
9 & Dynamic-MOPSO & 0.804353 & 7.239181 & 0.804353 & 0.804353 & 0.804353 \\
\hline
\end{tabular}

on table XIV are below 0.05 indicates the rejection of the null hypothesis using HVD metric. Clearly, we can conclude that DPb-MOPSO significantly performed the MOEAD, DNSGAII, PPS and dCOEA for all post-hoc procedures compared to the four MOPSO-based algorithms (dMOPSO, MOPSO, pbMOPSO and Dynamic-MOPSO) and the SGEA resulting the same significance level. For slight environmental changes in Table XVI, we can conclude the best significance of the DPb-MOPSO compared to DNSGA-II, PPS, MOEAD
TABLE XVII: Adjusted p-values over HVD for FDA and dMOP problems with $\tau_{t}=20$ and $n_{t}=10$ while MOPSO is the control method, $\alpha=0.05$.

\begin{tabular}{|c|c|c|c|c|c|c|}
\hline $\mathrm{i}$ & MOPSO vs. & unadjusted $p$ & $p_{\text {Bonf }}$ & $p_{\text {Holm }}$ & $p_{\text {Hochberg }}$ & $p_{L i}$ \\
\hline 1 & PPS & 0.000044 & 0.000393 & 0.000393 & 0.000349 & 0.000333 \\
2 & MOEAD & 0.000044 & 0.000393 & 0.000393 & 0.000349 & 0.000333 \\
3 & DNSGAII & 0.000088 & 0.00079 & 0.000614 & 0.000527 & 0.000669 \\
4 & dCOEA & 0.000088 & 0.00079 & 0.000614 & 0.000527 & 0.000669 \\
5 & SGEA & 0.005672 & 0.051047 & 0.028359 & 0.028359 & 0.041448 \\
6 & Dynamic-MOPSO & 0.23119 & 2.080713 & 0.924762 & 0.86883 & 0.638013 \\
7 & pbMOPSO & 0.649723 & 5.847504 & 1.949168 & 0.86883 & 0.832026 \\
8 & DPb-MOPSO & 0.649723 & 5.847504 & 1.949168 & 0.86883 & 0.832026 \\
9 & dMOPSO & 0.86883 & 7.819472 & 1.949168 & 0.86883 & 0.86883 \\
\hline
\end{tabular}

and dCOEA through IGD metric. While it is the same likewise the SGEA, MOPSO, pbMOPSO, Dynamic-MOPSO and dMOPSO algorithms. But, the APV values over HVD indicator reported on Table XVII highlight the significance of the MOPSO as the control method with the best rank and performed compared to PPS, MOEAD, DNSGA-II, dCOEA and SGEA over all post-hoc procedures. However, it fails compared to SGEA over Bonferroni-Dunn procedure and the four MOPSO-based algorithms for all post-hoc procedures 
FDA1
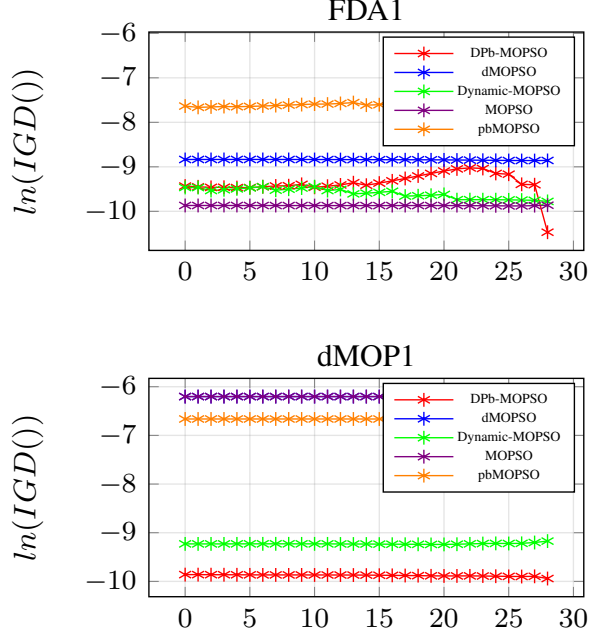

F5

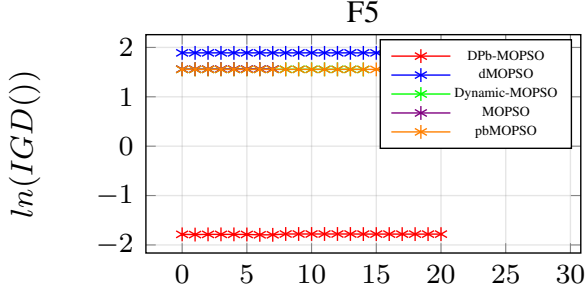

F8

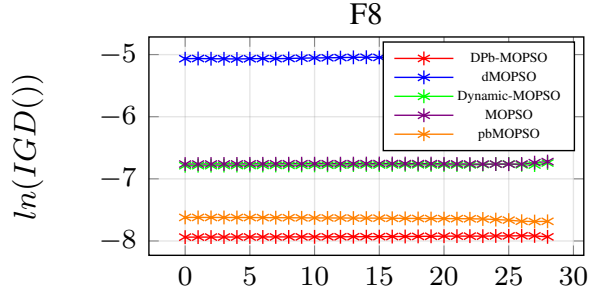

UDF1

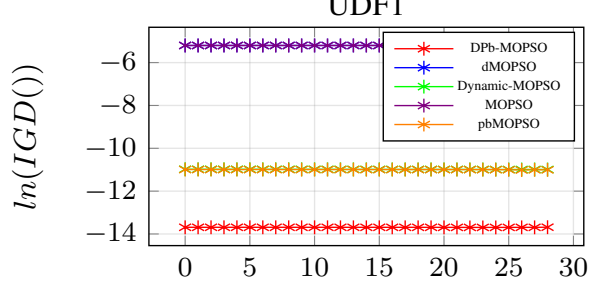

UDF5

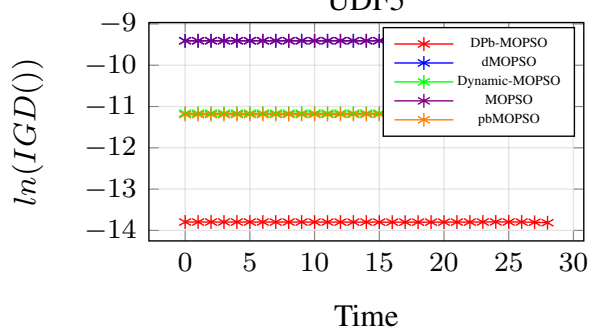

FDA2

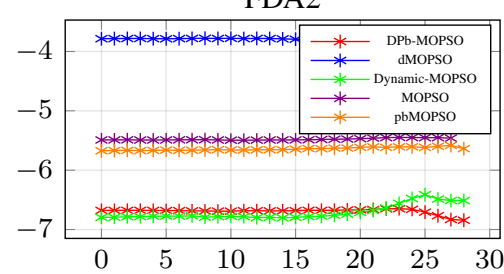

dMOP2

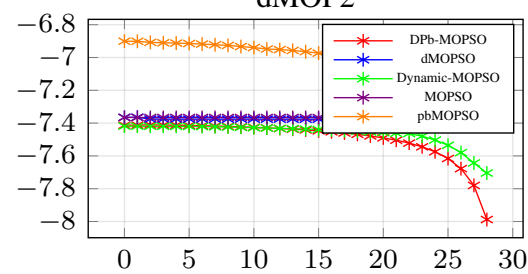

F6

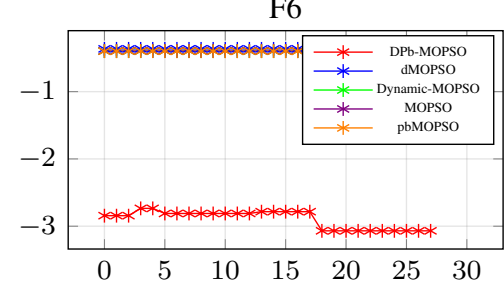

F9

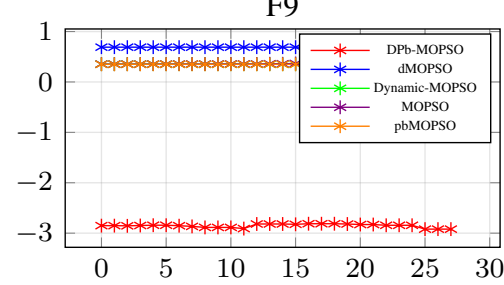

UDF2

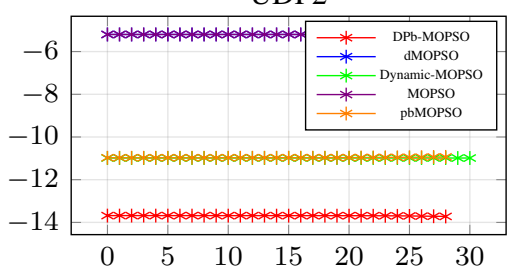

UDF6

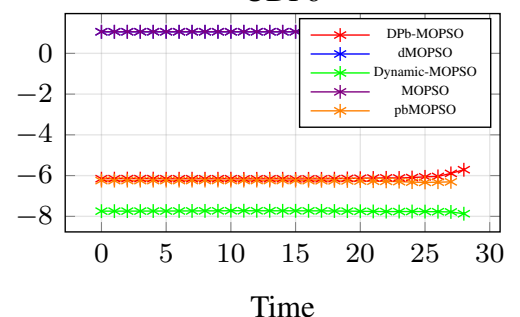

FDA4

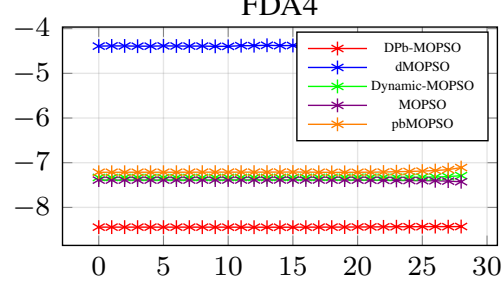

dMOP3

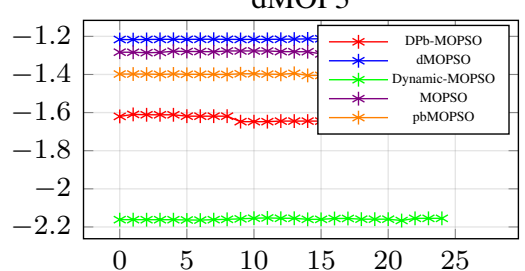

F7

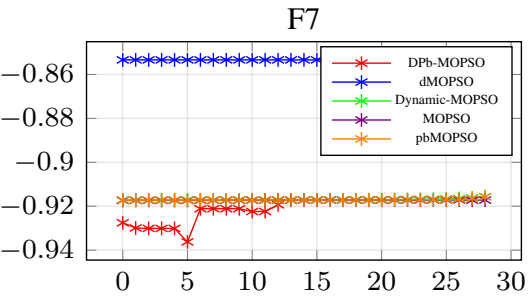

F10

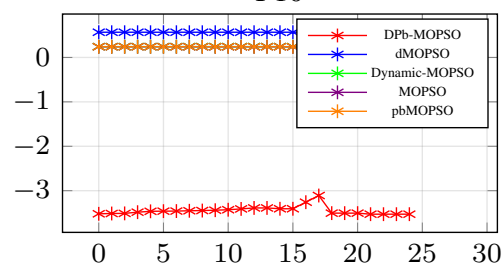

UDF4

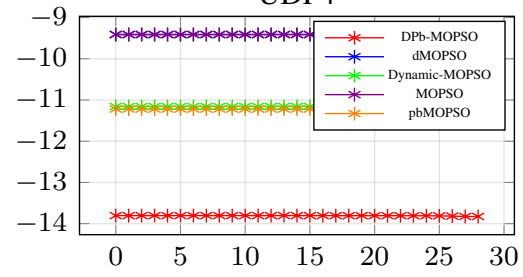

Time

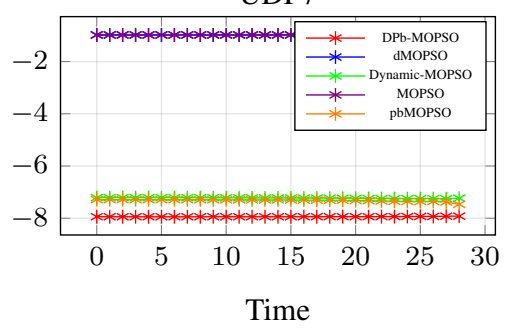

Fig. 3: Spectrum Lyapunov Exponent of MOPSO-based Algorithms for FDA, dMOP, F (ZJZ) and UDF Functions. 
when the null hypothesis is retained with significant level $\alpha$ $=0.05$ assuming an equal importance between DPb-MOPSO and MOPSO over HVD.

\section{Stability AnAlysis USING Lyapunov TheOREM}

The stability analysis is an important aspect when analyzing the robustness of dynamic systems. The Lyapunov's theorem developed by Alexandr Mikhailovich Lyapunov [19] is the well-known mechanism for stability analysis. This theorem aims to measure the growth of the initial values over time while the small differences from one instance to another is called Lyapunov Exponent (LE). In addition, LE can grow into very large differences to indicate the speed with which two initially close dynamics diverge or converge. The positive value of LE indicates a divergence whereas the negative value present the convergence in phase space. In [4], the difference between two points $t_{i}$ and $t_{j}$ over time is denoted by $t_{i}$, $t_{i+1}, t_{i+2} \ldots t_{i+n}$ and $t_{j}, t_{j+1}, t_{j+2} \ldots t_{j+n}$. The distance $d(k)$ between two sequences after $\mathrm{k}$ steps is computed using: $d(k)=\left|t_{i+k}-t_{j+k}\right|$ to measure the convergence and divergence over the Lyapunov Exponent in time-varying space. If the system is chaotic, $d(k)$ will initially rise exponentially with $k$ and we can compute and plot $\ln d(k)$ vs $k$ to estimate the Lyapunov Exponent (LE). When LE values are very small and close over time, this state indicates that the system is stable and reaches the same solution over time. In this study, we consider a set of IGD values during 30 independent runs of the five MOPSO-based algorithms over several DMOPs with $n_{t}$ and $\tau_{t}$ are equal to 10 . The independent IGD values are computed using the minimum Euclidean distance $d_{i}$ between i points in the generated $n P O F(|P O F|)$ and the true $P O F^{*}$ over time $t$. The stability analysis through Lyapunov Exponent for MOPSO-based systems is computed using $\ln (I G D())$. Figure 3 shown the spectrum of Lyapunov Exponent over FDA, dMOP, F and UDF functions. So, we can conclude that all Lyapunov exponent for all MOPSO-based algorithms over FDA1, FDA2, FDA4, dMOP1, dMOP2 and dMOP3 are under zero with negative values assuming that the systems converge over time. For UDF problems, the spectrum of Lyapunov exponent indicates the stability of DPb-MOPSO assuming the best convergence to stability with negative values of LE. The location points for F5, F9 and F10 indicate that the Lyapunov exponent diverges to deep positive values for MOPSO, dMOPSO, pbMOPSO and Dynamic-MOPSO systems compared to the spectrum of DPb-MOPSO that converge faster for all $\mathrm{F}(\mathrm{ZJZ})$ problems. Almost, the proposed $\mathrm{DPb}$ MOPSO algorithm has the best spectrum of convergence over many tested problems.

\section{CONCLUSION}

This study presents a novel Dynamic Pareto bi-level MultiObjective Particle Swarm Optimization (DPb-MOPSO) algorithm for solving different types of DMOPs (I, II and III). The proposed DPb-MOPSO presents a distributed architecture over two optimization levels, including a dynamism-handling strategy to detect and respond efficiently to changes. The Friedman two-way ANOVA test is used to evaluate the proposed $\mathrm{DPb}$ MOPSO compared to several MOEAs. Based on the statistical analysis (at 0.05 significance level), the DPb-MOPSO is shown to be a more robust algorithm in terms of its ability to ensure a good trade-off between convergence and diversity in a timedependent environment. Further the spectrum of Lyapunov exponents has been shown to be an efficient tool for analyzing periodic motions and stability analysis in dynamical systems. The superiority of the proposed method is clearly observed when handling DMOPs with two or three objectives including different types of changes in POS and POF. In conclusion, our study has demonstrated the novelty and robustness of the $\mathrm{DPb}-\mathrm{MOPSO}$ for dynamic multi-objective problems. However, these characteristics have yet to be explored for problems with more than three objectives. For future work, we will further enhance the proposed approach for Many Objective Optimization Problems (MaOOPs) as well as for pertinent feature selection in a real-world problem.

\section{ACKNOWLEDGMENT}

The research leading to these results has received funding from the Ministry of Higher Education and Scientific Research of Tunisia under the grant agreement number LR11ES48.

\section{REFERENCES}

[1] A. Aboud, R. Fdhila, and A. M. Alimi. Mopso for dynamic feature selection problem based big data fusion. In IEEE International Conference on Systems, Man, and Cybernetics, pages 003918-003923, Oct 2016.

[2] A. Aboud, R. Fdhila, and A. M. Alimi. Dynamic multi objective particle swarm optimization based on a new environment change detection strategy. In Derong Liu, Shengli Xie, Yuanqing Li, Dongbin Zhao, and El-Sayed M. El-Alfy, editors, Neural Information Processing, pages 258-268, Cham, 2017. Springer International Publishing.

[3] Z. Aimin, J. Yaochu, Z. Qingfu, S. Bernhard, and T. Edward. Predictionbased population re-initialization for evolutionary dynamic multiobjective optimization. In Evolutionary Multi-Criterion Optimization, pages 832-846, Berlin, Heidelberg, 2007. Springer.

[4] B. Biswal and C. Dasgupta. Stochastic neural network model for spontaneous bursting in hippocampal slices. PHYSICAL REVIEW E 66, 051908, 2002.

[5] C. A. Coello Coello and M. S. Lechuga. Mopso: a proposal for multiple objective particle swarm optimization. In Proceedings of the 2002 Congress on Evolutionary Computation., volume 2, pages 1051-1056, May 2002.

[6] R. Eberhart and J. Kennedy. Particle swarm optimization. In Neural Networks, pages 1942-1948. The 1995 IEEE International Conference on Neural Networks, Piscataway, New Jersey, IEEE Service Center, 1995.

[7] R. Fdhila, C. Walha, T. M. Hamdani, and A. M. Alimi. Hierarchical design for distributed mopso using sub-swarms based on a population pareto fronts analysis for the grasp planning problem. In 13th International Conference on Hybrid Intelligent Systems, pages 203-208, Dec 2013.

[8] C. K. Goh and K. C. Tan. A competitive-cooperative coevolutionary paradigm for dynamic multiobjective optimization. IEEE Transactions on Evolutionary Computation, 13(1):103-127, Feb 2009.

[9] M. Li H. Chen and X. Chen. Using diversity as an additionalobjective in dynamic multi-objective optimization algorithms. In 2009 Second International Symposium on Electronic Commerce and Security, volume 1, pages 484-487, May 2009.

[10] L. Hatzakis and D. Wallace. Dynamic multi-objective optimization with evolutionary algorithms: a forward-looking approach. In Proceedings of the 8th annual conference on Genetic and evolutionary computation, pages 1201-1208. ACM, 2006.

[11] E. J. Hughes. Multiple single objective pareto sampling. In The 2003 Congress on Evolutionary Computation, volume 4, pages 2678-2684 Vol.4, Dec 2003. 
[12] D. Molina J. Derrac, S. García and F. Herrera. A practical tutorial on the use of nonparametric statistical tests as a methodology for comparing evolutionary and swarm intelligence algorithms. Swarm and Evolutionary Computation, 1(1):3 - 18, 2011.

[13] S. Jiang and S. Yang. A steady-state and generational evolutionary algorithm for dynamic multiobjective optimization. IEEE Transactions on Evolutionary Computation, 21(1):65-82, Feb 2017.

[14] B. Udaya K. Deb, N. Rao and S. Karthik. Dynamic multi-objective optimization and decision-making using modified nsga-ii: A case study on hydro-thermal power scheduling. pages 803-817, Berlin, Heidelberg, 2007. Springer.

[15] S. Agarwal K. Deb, A. Pratap and T. Meyarivan. A fast and elitist multiobjective genetic algorithm: Nsga-ii. IEEE Transactions on Evolutionary Computation, 6(2):182-197, Apr 2002.

[16] M. Kim, T. Hiroyasu, M. Miki, and S. Watanabe. Spea2+: Improving the performance of the strength pareto evolutionary algorithm 2. pages 742-751, Berlin, Heidelberg, 2004. Springer.

[17] W. T. Koo, C. K. Goh, and K. C. Tan. A predictive gradient strategy for multiobjective evolutionary algorithms in a fast changing environment Memetic Computing, 2(2):87-110, Jun 2010

[18] K. B. Lee and J. H. Kim. Dmopso: Dual multi-objective particle swarm optimization. In 2014 IEEE Congress on Evolutionary Computation, pages 3096-3102, July 2014.

[19] A.M. Lyapunov. The general problem of the stability of motion. Kharkov Mathematical Society, Kharkov., 1892.

[20] J. Ortega M. Cámara and F. Toro. Parallel processing for multi-objective optimization in dynamic environments. In IEEE International Parallel and Distributed Processing Symposium, pages 1-8. IEEE, 2007.

[21] J. Ortega M. Cámara and F. Toro. Parallel multi-objective optimization evolutionary algorithms in dynamic environments. In Proceedings of the first international workshop on parallel architectures and bioinspired algorithms, pages 13-20, 2008.

[22] K. Deb M. Farina and P. Amato. Dynamic multiobjective optimization problems: test cases, approximations, and applications. IEEE Transactions on Evolutionary Computation, 8(5):425-442, Oct 2004.

[23] S. Nguyen, M. Zhang, M. Johnston, and K. C. Tan. Automatic design of scheduling policies for dynamic multi-objective job shop scheduling via cooperative coevolution genetic programming. IEEE Transactions on Evolutionary Computation, 18(2):193-208, April 2014.

[24] S. Bechikh R. Azzouz and L. Ben Said. Multi-objective optimization with dynamic constraints and objectives: new challenges for evolutionary algorithms. In Proceedings of the 2015 Annual Conference on Genetic and Evolutionary Computation, pages 615-622. ACM, 2015.

[25] S. Bechikh R. Azzouz and L. Ben Said. A dynamic multi-objective evolutionary algorithm using a change severity-based adaptive population management strategy. Soft Computing, 21(4):885-906, 2017.

[26] S. Bechikh R. Azzouz and L. Ben Said. Dynamic Multi-objective Optimization Using Evolutionary Algorithms: A Survey, pages 31-70. Springer International Publishing, Cham, 2017.

[27] P. N. Suganthan S. Biswas, S. Das and C. A. C. Coello. Evolutionary multiobjective optimization in dynamic environments: A set of novel benchmark functions. In IEEE Congress on Evolutionary Computation, pages 3192-3199, July 2014.

[28] A. Song, W. Chen, T. Gu, H. Yuan, S. Kwong, and J. Zhang. Distributed virtual network embedding system with historical archives and set-based particle swarm optimization. IEEE Transactions on Systems, Man, and Cybernetics: Systems, pages 1-16, 2019.

[29] J. Tsai, P. Chou, and J. Chou. Color filter polishing optimization using anfis with sliding-level particle swarm optimizer. IEEE Transactions on Systems, Man, and Cybernetics: Systems, 50(3):1193-1207, 2020

[30] Y. Wang and L. Li. Heterogeneous redundancy allocation for seriesparallel multi-state systems using hybrid particle swarm optimization and local search. IEEE Transactions on Systems, Man, and Cybernetics - Part A: Systems and Humans, 42(2):464-474, 2012.

[31] Q. Zhang and H. Li. Moea/d: A multiobjective evolutionary algorithm based on decomposition. IEEE Transactions on Evolutionary Computation, 11(6):712-731, Dec 2007.

[32] Zhuhong Zhang. Multiobjective optimization immune algorithm in dynamic environments and its application to greenhouse control. Applied Soft Computing, 8(2):959 - 971, 2008.

[33] B. Zheng. A new dynamic multi-objective optimization evolutionary algorithm. In Third International Conference on Natural Computation, volume 5, pages 565-570, Aug 2007.

[34] A. Zhou, Y. Jin, and Q. Zhang. A population prediction strategy for evolutionary dynamic multiobjective optimization. IEEE Transactions on Cybernetics, 44(1):40-53, Jan 2014.

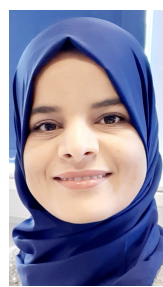

Ahlem Aboud She is currently a $\mathrm{PhD}$ student in computer science in the ISITCom, Sousse of University and a PhD member of the REGIM-lab: REsearch Group on Intelligent Machines at the National school of engineers of Sfax (ENIS). She received the engineering degree in 2015 in the Higher Institute of Computing and Multimedia of Sfax. She is currently IEEE student member since October 2015. His research interests include, dynamic multi-objective optimization problem, evolutionary computation and collective intelligence methods.

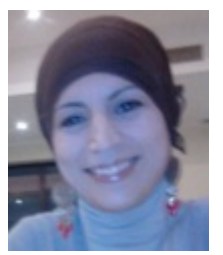

Raja Fdhila She holds an engineering degree in computer science and a Master's degree in automation and signal processing from the National School of Engineers of Tunis (ENIT) in 2005 and 2007 respectively. She obtained her doctorate in computer systems engineering from the National School of Engineers of Sfax (ENIS) in 2017. She is currently a member of the REGIM-lab: REsearch Group on Intelligent Machines at the National school of engineers of Sfax (ENIS). She works mainly in the field of artificial intelligence, and is particularly interested in multi-objective optimization, collective intelligence, multi-agent systems,... She has been an IEEE member since 2008.

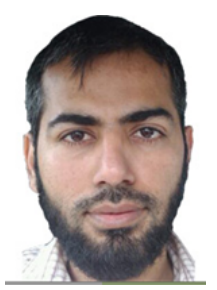

Amir Hussain he received his B.Eng (highest 1st Class Honours with distinction) and Ph.D degrees, from the University of Strathclyde, Glasgow, U.K., in 1992 and 1997, respectively. Following postdoctoral and academic positions at the Universities of West of Scotland (1996-98), Dundee (1998-2000) and Stirling (2000-18) respectively, he joined Edinburgh Napier University (in Scotland, UK) in 2018 as Professor and founding Head of the Data Science and Cyber Analytics (DSCA) Research Group (managing 20 academics and research staff). As part of the latter, he is also founding Head of the Cognitive Big Data and Cybersecurity (CogBiD) Research Lab.

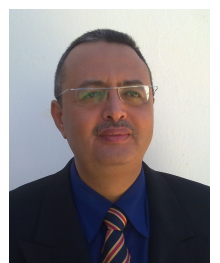

Adel M. Alimi (S'91-M'96-SM'00) was born in Sfax, Tunisia, in 1966. He received the Degree in electrical engineering in 1990, the Ph.D. degree in electrical and computer engineering from the Polytechnic University of Montréal, Montréal, QC, Canada, in 1995, and the HDR degree in electrical and computer engineering from the National Engineering School of Sfax, Sfax, in 2000. He is currently a Professor of electrical and computer engineering with the University of Sfax, Sfax. His current research interests include applications of intelligent methods (neural networks, fuzzy logic, and evolutionary algorithms) to pattern recognition, robotic systems, vision systems, industrial processes, intelligent pattern recognition, learning, analysis, and intelligent control of large-scale complex systems. Prof. Alimi is a member of IAPR, INNS, and PRS. He is a member and an Associate Editor of the Editorial Board of many international scientific journals, including Pattern Recognition Letters, Neurocomputing, Neural Processing Letters, International Journal of Image and Graphics, Neural Computing and Applications, International Journal of Robotics and Automation, and International Journal of Systems Science. He was a Guest Editor of several special issues of international journals, including Fuzzy Sets and Systems, Soft Computing, the Journal of Decision Systems, Integrated Computer-Aided Engineering, and Systems Analysis Modeling and Simulations. 